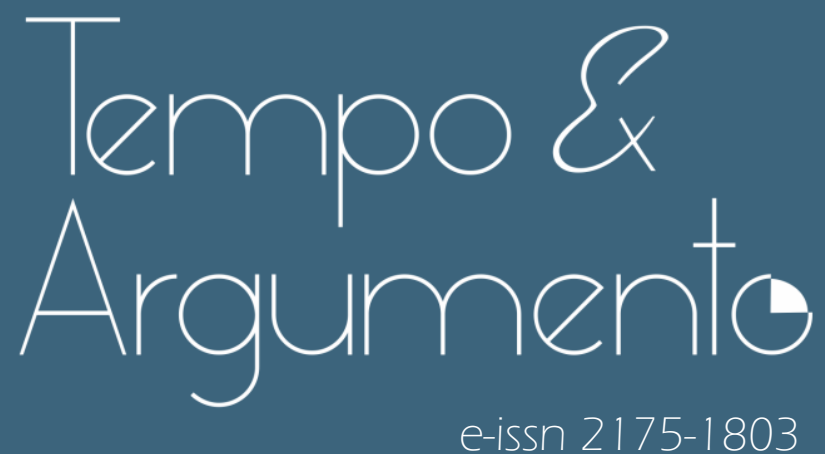

\title{
Museos pedagógicos universitarios en ciudades educadoras del tiempo presente: divulgación del patrimonio histórico educativo
}

- Pablo Álvarez Domínguez

Doctor en Pedagogía por la Universidad de Sevilla (US).

Profesor contratado doctor de la Facultad de CC. de la Educación de la Universidad de Sevilla. Secretario de la Sociedad Española para el Estudio del Patrimonio

Histórico Educativo (SEPHE). Secretario del Museo Pedagógico de la Facultad de Ciencias de la Educación de la Universidad de Sevilla (US).

Sevilla - ESPANHA

https://investigacion.us.es/sisius/

pabloalvarez@us.es

(D) orcid.org/0000-0003-0538-2565

Para citar este articulo:

ÁLVAREZ DOMíNGUEZ, Pablo. Museos pedagógicos universitarios en ciudades educadoras del tiempo presente: divulgación del patrimonio histórico educativo.

Tempo e Argumento, Florianópolis, v. 12, n. 31, e020 1, set./dez. 2020.

doi)

http://dx.doi.org/10.5965/2175180312312020e0201

Recebido: 16/05/2020

Aprovado: 13/10/2020 


\title{
Museos pedagógicos universitarios en ciudades educadoras del tiempo presente: divulgación del patrimonio histórico educativo
}

\begin{abstract}
Resumen
Reclamar la importancia de la educación en la ciudad es una demanda histórica y un reto emergente para la sociedad actual, a la que se le encomienda velar por el desarrollo cultural y formativo de sus habitantes. La Historia de la Educación como disciplina, tiene en sus manos la oportunidad de desarrollar una política de divulgación científica propia que acerque el conocimiento histórico educativo a la sociedad, con el fin de poner en valor la cultura de la escuela e implicar a la ciudadanía en el estudio y difusión del patrimonio educativo. La historia más reciente ha puesto de manifiesto que en el proceso de socialización y difusión del conocimiento a la comunidad, tienen un importante protagonismo las Universidades. Ese artículo, de corte descriptivo, trata de argumentar que la comunidad de investigación en Historia de la Educación encuentra en los Museos Pedagógicos universitarios un novedoso recurso didáctico para divulgar el conocimiento patrimonial histórico educativo y desarrollar su compromiso sociocultural con la sociedad. El trabajo, centrándose en el caso del Museo Pedagógico de la Facultad de Ciencias de la Educación de la Universidad de Sevilla (España), trata de estudiar su papel en el desarrollo de su función divulgativa y de transferencia del conocimiento para acercar el patrimonio educativo a quienes componen la ciudad, detallando el conjunto de formas, acciones y actividades de divulgación que realiza. Concluye con que mediante las mismas, el museo contribuye a la formación de una cultura histórico-educativa en la ciudadanía.
\end{abstract}

Palabras clave: Museo Especializado. Patrimonio Cultural. Historia de la Educación. Divulgación Científica.

\section{University pedagogical museums in educating cities of the present time: popularization of the educational historical heritage}

\begin{abstract}
Claiming the importance of education in the city is a historical demand and an emerging challenge for today's society, which is charged with ensuring the cultural and educational development of its inhabitants. The History of Education as a scientific discipline, has in its hands the opportunity to develop its own scientific dissemination policy that brings educational historical knowledge closer to society, in order to value the culture of the schoolinvolving citizens in the study and dissemination of educational heritage. Recently history has shown that in the process of socialization and dissemination of knowledge to the community, universities have an important role. This descriptive article attemptsto argue that the educational history research community finds in the university pedagogical museums a new didactic resource to disseminate the historical educational heritage knowledge and develop its sociocultural commitment to society. The work, focusing on the case study of the Pedagogical Museum of the Faculty of Educational Sciences of the University of Seville (Spain), tries to study its role in the development of its dissemination and knowledge transfer function to bring heritage closer educational to those who make up the city, detailing the set of forms, actions and outreachdissemination activities they carry out. It concludes that through these, the museum contributesto foster a historical-educational culture in the citizenship.
\end{abstract}

Keywords: Specialized Museums. Cultural Heritage. Educational History. Scientific Popularization. 
Museos pedagógicos universitarios en ciudades educadoras del tiempo presente: divulgación del patrimonio histórico educativo

Pablo Álvarez Domínguez

1. Introducción: justificación, objeto de estudio y planteamiento de la investigación ${ }^{1}$

El acceso al conocimiento y a la cultura, así como a la comunicación pública de la ciencia (ALCÍBAR, 2015), es indispensable para que una sociedad tome conciencia del mundo en el que habita. Y en este sentido, el impulso de lo científico debe tener un papel crucial en las políticas de los gobiernos. La promoción de políticas públicas nacionales e internacionales abiertas y orientadas a la comunicación, difusión y transferencia del conocimiento a la ciudadanía, ha de constituir una prioridad natural para nuestras sociedades, y con ello, para nuestras ciudades. A través de las instituciones que tienen a su servicio, deben hacer un esfuerzo ímprobo por favorecer el fomento de una cultura de base científica, tecnológica, histórica y patrimonial, que contribuya a estimular y a alfabetizar a la población, en general, y a favorecer mecanismos que faciliten el diálogo de las personas con la sociedad, la ciencia y la cultura (PERRAULT, 2013).

El presente trabajo parte de la necesidad de establecer una primera aproximación a un conjunto de ideas y consideraciones fundamentales, orientadas a pensar la ciudad que queremos, a proyectarla, a transitarla, a cuestionarla, e incluso a ponerla en valor como escenario especialmente apropiado para visibilizar el patrimonio educativo desde una pedagogía museística de carácter histórico y patrimonial. Y de manera particular se quiere incidir en el papel que dentro de la ciudad pueden llegar a ejercer las universidades a través del desarrollo de la cultura, enmarcándose ésta dentro de la tercera misión (ARIÑO, 2017) que tiene encomendada la institución universitaria en la actualidad ${ }^{2}$. La universidad del presente, y con ella la comunidad de

\footnotetext{
${ }^{1}$ Este trabajo encuentra su base en el desarrollo de los siguientes proyectos de investigación y divulgación de la ciencia: a) Proyecto: "Difusión y divulgación del patrimonio y memoria de la escuela del ayer a través del Museo Pedagógico de la Facultad de Ciencias de la Educación de la Universidad de Sevilla". Convocatoria de Ayudas para Actividades de Divulgación Científica.Universidad de Sevilla. V Plan Propio de Investigación, 2016 (Acción III.2.) (Resolución del 9 de junio de 2016); b) Proyecto: "Divulgación de la Ciencia y Tecnología a través del patrimonio histórico educativo del Museo Pedagógico de la Facultad de Ciencias de la Educación de la Universidad de Sevilla". Convocatoria de Ayudas para Actividades de Divulgación Científica. Universidad de Sevilla. VI Plan Propio de Investigación y Transferencia, 2019 (Acción III.3.) (Resolución del 29 de abril de 2019). Investigador principal: el autor del trabajo.

2 Si reconocemos que las tres funciones fundamentales de la universidad son la formación, la investigación y la responsabilidad social y cultural, hemos de añadir también una cuarta, que tiene que ver con la transferencia del conocimiento (TRENCHER, 2014)
} 
historiadores/as de la educación, tienen que ser capaces de encontrar en la ciudad (ANDRADE, 2016), una potente herramienta didáctica al servicio de la enseñanza de la Historia de la Educación. Y a esto, tenemos que añadir el uso de los museos pedagógicos universitarios (ÁLVAREZ, 2016; ASCENZI, BRUNELLI; MEDA, 2019; RABAZAS; RAMOS, 2016; 2017), concibiéndolos como pilares didácticos que están contribuyendo a dar a conocer más significativamente la disciplina histórico educativa y el patrimonio de la educación a una parte importante de la sociedad. Desde esta perspectiva, quizás desde los museos pedagógicos que se integran en las universidades, podamos colaborar en el reto de contribuir a dotar a las personas de los instrumentos necesarios para que puedan comprender su entorno y su presente, y sean capaces de explicar su propia historia a través de un acercamiento a la ritualización y musealización de teorías, prácticas y objetos del mundo de la escuela.

La ciudad es un gran receptáculo de las culturas ligadas a nuestra existencia. Las ciudades son el motor del conocimiento científico de nuestra sociedad. Y en efecto, se trata de un escenario que educa, tanto en cuanto seamos capaces de entenderlo como un contenedor de patrimonio, depositario de valores culturales y generador de experiencias educativas. Históricamente, la ciudad ha sido considerada como un lugar imaginado, especialmente propicio para plasmar nuestros ideales ${ }^{3}$. Por ello, somos conscientes de que la ciudad es un escenario educador, en la medida en que cada lugar de la misma cuenta con un particular potencial educativo. Así, cada espacio de la ciudad puede ser entendido como un aula permanente viva y abierta al conocimiento y a la experiencia compartida, y además, como un motivo para el aprendizaje, pues cada manifestación cultural, artística o estética, es una oportunidad para el encuentro con la cultura. Ciertamente, no puede pasar desapercibida la oportunidad de repensar la ciudad en clave pedagógica y cultural, entendiéndola como un verdadero escaparate social de posibilidades educativas, experiencias culturales colectivas y vivencias personales. Una ciudad que educa - proyectada como marco y agente educador-, es una ciudad que muestra a sus habitantes

\footnotetext{
${ }^{3}$ Por ejemplo, el propio Platón imaginó la República ideal como una ciudad; San Agustín proyectó la ciudad celestial como la ciudad del nuevo paraíso; Tomás Moro trazó una Nova Insula Utopia, donde no habría ni ricos, ni pobres; y F. Bacon, por ejemplo, fue capaz de imaginar la New Atlantis o la ciudad de los sabios y los científicos.
} 
su historia, les ayuda a entender su presente y les inspira para proyectar su futuro; y además, en todo momento les interpela para que aprendan a cuestionar todo lo que se les viene dando.

Conscientes de que la ciudadanía tiene derecho a descubrir y a reconstruir la ciudad en la que habita, no podemos obviar nuestro derecho a participar, e incluso a formar parte de la vida cultural de la sociedad que nos acoge, enriqueciéndonos además con el conocimiento de la ciencia y la cultura. Trilla (1997), nos propone considerar tres posibles caminos para dar valor a una ciudad educadora, capaz de encontrar en lo científico y en lo cultural la base de nuestra identidad personal y colectiva. Con respecto a esto, nos recuerda: a) la necesidad de concebir la ciudad como un entorno o un contenedor patrimonial, sobre todo si nuestro objetivo se centra en el aprender en la ciudad; b) la conveniencia de considerar la ciudad como fuente o agente educativo propiamente dicho, básicamente si nuestra intención reside en aprender de la ciudad; y c) la oportunidad de proyectarla como objetivo o como contenido de la educación, si lo que nos interesa es aprender la ciudad. De esta forma, partimos de la premisa de que cuando alguien aprende en y de la ciudad, realmente aprende la ciudad. Como señala Pérez (2005, p. 141), el espacio de la ciudad merece ser "recontextualizado desde una perspectiva comunitaria, pues es la propia comunidad la que usa ese espacio, disfrutándolo y sufriéndolo con sus necesidades, carencias, vivencias y prácticas". Así pues, las ciudades se convierten en espacios creados y legitimados por la propia comunidad para dar sentido a su cultura y a su identidad.

El principal sentido y objetivo de nuestro trabajo reside en establecer un incipiente juego académico y cultural de relaciones dialógicas entre la ciudad, la universidad, los museos pedagógicos, el patrimonio educativo y la divulgación del conocimiento histórico educativo. Sobre esta base, vamos a tratar de justificar y evidenciar a través de un estudio de caso intrínseco-entendido como examen particular, descriptivo y heurístico de un ejemplo en acción-(YACUZZI, 2005), cómo el Museo Pedagógico Universitario puede llegar a convertirse dentro de la ciudad en un agente de dinamización cultural histórico educativa importante a la hora de participar en la difusión de la historia, la cultura, la memoria y el 
Museos pedagógicos universitarios en ciudades educadoras del tiempo presente: divulgación del patrimonio histórico educativo

Pablo Álvarez Domínguez

patrimonio de la educación (MARTíNEZ et al., 2016). Interés que nos viene dado en aras de poder expresar y reconocer que la comunidad de historiadores/as de la educación, ha encontrado en los museos pedagógicos universitarios en la actualidad, un sugestivo y dinamizador recurso didáctico, especialmente atrayente para divulgar el conocimiento patrimonial histórico educativo y desarrollar su compromiso sociocultural para con la sociedad.

La pertinencia y el potencial investigador de un estudio de caso se basan precisamente en el supuesto de que lo global se refleja en lo local (HAMEL, DUFOUR; FORTIN, 1993); esto es, en la naturaleza holográfica de la realidad, tratando de describir cualquier proceso de una unidad de vida en sus diversas interrelaciones con su escenario cultural. Por ello, basándonos en este planteamiento metodológico, y al tratarse de un problema a estudiar aún incipiente (YACUZZI, 2005), recogemos de forma descriptiva diferentes tipos de informaciones cualitativas mediante el uso de la observación experiencial, análisis de grabaciones de video, entrevistas, notas de campo y otros documentos dispares como memorias, crónicas y reseñas ligadas al caso de un Museo Pedagógico concreto. Lo que nos ayudará a desvelar un conjunto de prácticas y significados desconocidos en el ámbito de la divulgación del patrimonio educativo, tal vez un tanto invisibilizados para la ciudadanía e incluso para muchos historiadores/as de la educación. En este trabajo en concreto, centrándonos en lo local, tal y como se ha señalado, nos encargaremos de abordar el estudio de una iniciativa museística universitaria, ligada a una trayectoria concreta en torno a la divulgación del patrimonio histórico educativo desde un museo universitario ${ }^{4}$.

\footnotetext{
${ }^{4}$ Hágase notar, no obstante, la labor que en este sentido vienen desarrollando los distintos museos pedagógicos universitarios existentes en España. A modo de ejemplos, cfr. ÁLVAREZ Y PAYÀ, 2015; ÁLVAREZ, 2016; DÁVILA Y NAYA, 2017; MARTÍN Y RAMOS, 2008; RABAZAS Y RAMOS, 2016; 2017. A nivel internacional, es de justicia reconocer el papel que ejercen un número importante de museos pedagógicos universitarios en países como: a) Italia: Museo dellascuola «Paolo e OrnellaRicca». Università degli Studi di Macerata; Centro di documentazione e ricerca sulla storia del libro scolastico e della letteratura per l'infanzia - CESIS - Università deglistudi del Molise; Centro di ricerca e documentazionesullastoriadell'educazione in Alto Adige - Libera Università di Bolzano; Museo dell'educazione - UniversitàdegliStudi di Padova; Museo storicodelladidattica «Mauro Laeng» - UniversitàdegliStudi Roma 3. b) Francia: Maison de la Recherche en SciencesHumaines - Université de Caen; Institut Français de l'Éducation (IFÉ) ÉquipeHistoire de l'Éducation; Centre d'Etudes, de Documentation et de Recherches en Histoire de l'Education (CEDRHE) - Faculté d'Éducation - Université Montpellier 2. c) Grecia: Centre for
} 
Museos pedagógicos universitarios en ciudades educadoras del tiempo presente: divulgación del patrimonio histórico educativo

Pablo Álvarez Domínguez

La creación del Museo Pedagógico de la Facultad de Ciencias de la Educación de la Universidad de Sevilla (ÁLVAREZ, NúÑEZ; REBOLLO, 2016), ejemplifica un caso de traslación de un proyecto de investigación en equipo ${ }^{5}$ a un plan con clara vocación divulgativa universitaria orientada a la formación y desarrollo cultural de la ciudadanía. A lo largo de este artículo, y tomando como telón de fondo la creación de estos espacios culturales universitarios en el marco de ciudades educadoras, se pretende dar cuenta de cómo podemos transformar un trabajo de investigación académica en un producto de interés sociocultural, a través del desarrollo de un proceso de divulgación orientado a poner en valor el estudio del patrimonio educativo en la sociedad en la que nos encontramos. De esta forma, el interés científico de este trabajo reside principalmente en la reflexión y puesta en valor que se presenta en relación con la importancia que están llegando a alcanzar los museos pedagógicos en la universidad, centrándonos en el análisis de los diversos valores que en relación con la divulgación del patrimonio educativo, representa en concreto el caso del museo objeto de estudio. El artículo se estructura en varias partes, que articuladas entre sí, tratan de responder al objeto de estudio que nos ocupa. En primer lugar, tras establecerse los principales pilares sobre los que se sostienen el papel pedagógico y cultural que tienen las ciudades educadoras de la actualidad, en un segundo apartado nos encargamos de hacer notar cómo el desconocido y no

\footnotetext{
the Study\&Research of the History of Education and the Teaching Profession (CSRHETP) Museum of Education of the University of Crete in Rethymno. d) Alemania: Reading Primers Special Interest Group - International Society for Historical and Systematic Research on Schoolbooks - Bonn. e) Polonia: Centrum Badań Literatury dla Dzieci i Młodzieży - CBLDM (Centre forResearchonChildren's and Young AdultLiterature) - Uniwersyt et Wrocławski. f) Bélgica: Centrum voor Historische Pedagogiek - Katholieke Universiteit Leuven. g) Eslovenia: Slovenskišolskimuzej - SSM -Ljubljana. h) Colombia: Museo Pedagógico Colombiano (Universidad Pedagógica Nacional). i) Rusia: Kazan Federal University; Russian Academy of Education - Moscow; State Scientific Pedagogical Library "K.D. Uschinskij" - Moscow. j) Estados Unidos: GraduateSchool of Library and InformationScience - University of Illinois. k) Brasil: Centro de Memória da Educação da Faculdade de Educação/Universidade de Sao Paulo; Centro de Memória da Educação (CME) - Faculdade de Educação - Universidade Estadual de Campinas; Centro de Memória UERJ; Centro de Memória da UFRRJ.

${ }^{5}$ A la creación del Museo Pedagógico en el año 2012 le anteceden unos quince años de trabajo y esfuerzos continuados, que tienen su base en un par de proyectos de investigación competitivos liderados por la Dra. Gómez García: a) Proyecto: "Creación del Museo Pedagógico Andaluz". Ministerio de Ciencia y Tecnología del Gobierno de España. Plan Nacional de Investigación Científica, Desarrollo e Innovación Tecnológica. (I+D+I) (2004-07). (Referencia: HUM2004-03305) y b) Proyecto: "Museo Didáctico Virtual del Patrimonio Histórico-Educativo Andaluz". Proyectos de investigación de excelencia de la Junta de Andalucía. Consejería de Innovación, Ciencia y Empresa. Unión Europea, FEDER (2006-09). (Referencia: EXC/2005/HUM-562).
} 
suficientemente valorado patrimonio histórico educativo de las ciudades, se presenta como un importante pilar cultural e identitario a ser explotado por parte de la comunidad científica de historiadores de la educación, que tiene justamente como objeto de estudio la cultura material e inmaterial de la educación. En tercer lugar, habiéndose puesto de manifiesto que este patrimonio puede contribuir a engrandecer el legado cultural de la ciudad, se procede en un cuarto apartado a hacer notar el papel que tienen las universidades y sus museos pedagógicos a la hora de comunicarlo, difundirlo y acercarlo a la sociedad. En el quinto y último apartado, nos centramos en estudiar cómo se ha hecho frente desde el Museo Pedagógico de la Facultad de Ciencias de la Educación de la Universidad de Sevilla al reto de divulgar la historia, la memoria y el patrimonio de la educación, a través de diferentes formas, acciones y actividades divulgativas. Estudio que abre las puertas a futuras investigaciones comparadas centradas en el caso de los museos pedagógicos universitarios de España y/o de otros países internacionales.

\section{Las ciudades educadoras como contenedores patrimoniales en el presente cultural}

En los últimos decenios, estamos asistiendo a una creciente voluntad de configurar, entender y ver la ciudad como un importante agente educador por y para la ciudadanía. La ciudad y su entorno se comprenden hoy como "un espacio educativo que puede ofrecer un amplio horizonte de oportunidades para el aprendizaje mediante sus múltiples ámbitos: escolar, social, cultural, económico y político" (COMA; SANTACANA, 2010, p. 55). De esta forma, lo que no puede hacer la institución escolar sola, tal vez lo pueda hacer en compañía de la ciudad, en la medida en que contribuya al objetivo común de educar para conseguir una ciudadanía formada y comprometida. Tal y como señala Alfieri (1991, p. 85), "la ciudad de hoy es en su conjunto el laboratorio adecuado para una educación coherente con las expectativas culturales que la sociedad alimenta frente al sistema formativo". Por ello, con la intención de ayudar a la ciudadanía a acumular un nutrido conjunto de experiencias educativas y patrimoniales de base, que tengan como objetivo enseñar a mirar e interpretar el mundo que nos rodea, la ciudad puede llegar a desempeñar un papel transcendental. 
Una ciudad educadora es una ciudad con personalidad propia y con capacidad para sumar y ayudar a que se relacionen unas personas con otras, para dar voz a los silencios del pasado, para sacar a relucir ausencias históricas, para visibilizar el ajuar patrimonial de nuestra identidad personal, para invertir en cultura y por la cultura ${ }^{6}$, y para formar permanentemente a su población. Es esta ciudad la encargada de promover la participación de sus vecinos/as y de fomentar el diálogo intergeneracional, el asociacionismo, el activismo, la defensa de su patrimonio y de la identidad, la promoción de políticas sustentables, la innovación, la creatividad, la inclusión y la diversidad, generando así un gobierno abierto que permita el control de la gestión cultural por parte de sus habitantes. No obstante, conscientes de que la ciudad educadora no puede pretender por sí sola ser la clave de la resolución de todas las dificultades que tiene la sociedad y de la superación de todos los retos que se presentan necesarios acometer, sí que resulta de especial relevancia la necesidad de "generar un clima de calidad cívica y de convivencia, que permita tomar conciencia de los cambios, orientarse mejor en su complejidad, atenuar y asegurar algunos de sus efectos negativos y contribuir a la potenciación de oportunidades" (DEL POZO, 2008, p. 28).

La idea de ciudadanía no debe estar vinculada solo a los derechos individuales. Tal y como pone de manifiesto Camps (2018), ha de incluir aquellos vínculos capaces de unir al ciudadano/a con la comunidad. Por eso, una ciudad que aspira a educar de verdad, ha de tomar conciencia y planificar acciones culturales y pedagógicas de diversa índole, mejorando las oportunidades y la vida de las personas que la habitan, y estando dispuesta a escuchar y a sumar las voces y las propuestas de la sociedad. Y en estos tiempos que corren, tal vez necesitemos más que nunca profundizar culturalmente hablando en la sociedad que compartimos. Entendamos la cultura como "el modo socialmente aprendido de vida que se encuentra en las sociedades humanas y que abarca todos los

\footnotetext{
- Con respecto a esto, resulta reseñable el desconocido papel que en lo que respecta a invertir en cultura y por la cultura, desarrolla el Fondo Internacional para la Diversidad Cultural (FIDC), que es un fondo formado por diferentes donantes cuya creación fue prevista por el artículo 18 de la Convención de 2005 sobre la Protección y la Promoción de la Diversidad de las Expresiones Culturales. Se trata de un instrumento orientado a invertir en proyectos que conducen al cambio estructural, demostrando el valor y las oportunidades que la cultura trae a los procesos de desarrollo sostenible. Cfr. https://es.unesco.org/creativity/ifcd
} 
Museos pedagógicos universitarios en ciudades educadoras del tiempo presente: divulgación del patrimonio histórico educativo

Pablo Álvarez Domínguez

aspectos de la vida social, incluidos el pensamiento y el comportamiento" (HARRIS, 2007, p. 17). Son las maneras de vivir y las expresiones artísticas, literarias, etc., de las sociedades las que van a determinar su propia cultura. Por ello, conviene no olvidar que la cultura nos va a marcar lo que valoramos de uno mismo y de los demás. La cultura nos da identidad y, en consecuencia, ha de ser el Estado a través de las instituciones públicas, el encargado de garantizar su socialización y el acceso de todos/as a la misma. En este momento, necesitamos ciudades que se reinventen y que aprendan a repensar y a reutilizar sus espacios culturales para contribuir a la educación de sus ciudadanos/as, pues resulta prácticamente indiscutible que una ciudad educadora es aquella que ofrece con generosidad y actitud de servicio todo su potencial formador y cultural a toda la comunidad.

El presente de las ciudades educadoras tiene su origen en la Carta inicial de principios básicos para el impulso educativo de la ciudad, aprobada en el I Congreso Internacional de Ciudades Educadoras, celebrado en Barcelona (España), en 19907 . Esta carta estructura su contenido y su sentido en torno a 3 ejes básicos: a) El derecho a la ciudad educadora; b) El compromiso de la ciudad; y c) El servicio integral a las personas. Así mismo, en ella se recogen 20 principios fundamentales ${ }^{8}$ en los que tienen que apoyarse aquellas ciudades que intenten depositar su confianza en la educación y en la cultura como medio y fin para el desarrollo de la ciudadanía. Las ciudades educadoras se hacen reales a través de

\footnotetext{
Esta carta fue revisada posteriormente en el III Congreso Internacional de Ciudades Educadoras, celebrado en Bolonia (Italia), en 1994, y adaptada en lo que a planteamientos respecta para atender a nuevos retos y necesidades sociales en el IV Congreso Internacional de Ciudades Educadoras, celebrado en Génova (Italia), en 2004.

${ }^{8}$ La Carta se fundamenta en la Declaración Universal de Derechos Humanos (1948), en el Pacto Internacional de Derechos Económicos, Sociales y Culturales (1966), en la Convención sobre los Derechos de la Infancia (1989), en la Declaración Mundial sobre Educación para Todos (1990), y en la Declaración Universal sobre la Diversidad Cultural (2001). Sus 20 principios se resumen a continuación: 1) Igualdad ante posibilidades formativas; 2) Educar en y para la diversidad; 3) Fomento de proyectos intergeneracionales; 4) Políticas que promocionen a los habitantes; 5) Políticas educativas transversales e innovadoras; 6) Tener en cuenta las necesidades de los habitantes; 7) Visibilizar la identidad de la ciudad; 8) Armonía entre nuevas necesidades y referentes del pasado; 9) Fomentar la participación ciudadana; 10) Dotación de espacios, recursos y equipamientos; 11) Garantizar la calidad de vida; 12) Campañas y proyectos que ayuden a crecer colectivamente; 13) Debates e intercambios entre ciudades; 14) Formación para educadores y familias; 15) Orientación y participación en actividades sociales; 16) Fomentar cohesión social entre barrios; 17) Cooperación con la sociedad civil; 18) Estímulo y fomento de la participación; 19) Informar y facilitar recursos; y 20) Formación en valores y prácticas democráticas. Cfr. https://www.edcities.org/carta-de-ciudades-educadoras/
} 
un proyecto educativo de ciudad, y en este sentido, resulta especialmente destacable el papel que está ejerciendo la Asociación Internacional de Ciudades Educadoras (AICE) (1994) ${ }^{9}$, asociación sin fines de lucro que se constituyó como una estructura colaborativa entre los gobiernos locales comprometidos con la mencionada Carta, y que se concibe como la hoja de ruta de las ciudades que la componen.

Si las ciudades de la actualidad constituyen espacios privilegiados para educar, no cabe duda de que también tienen en sus manos la posibilidad de ayudarnos a hacernos más humanos acercándonos a la cultura. Reconociendo la existencia de diferentes propuestas pedagógicas que han contribuido al desarrollo de ciudades educadoras (BOSCH, 2008; DÍEZ; RODRÍGUEZ, 2018; SCE, 2008; TONUCCI, 2015), traemos a colación el papel que este sentido implementa la Red Estatal de Ciudades Educadoras de España (RECE), que basa su quehacer en una educación que parte del uso del patrimonio como eje estratégico, brindándonos un amplio conjunto de experiencias educativas patrimoniales que bien podemos tomar como referente a la hora de poner en valor nuestro patrimonio como legado histórico educativo ${ }^{10}$. Al mismo tiempo, la AICE también pone a nuestra disposición el Banco Internacional de Documentos de Ciudades Educadoras (BIDCE), una base de datos que contiene más de 500 experiencias pedagógico patrimoniales ${ }^{11}$, que muestran e ilustran diferentes concreciones de los principios de la Carta de Ciudades Educadoras, y pueden resultar estímulo e inspiración para en el marco de nuestras ciudades, fraguar novedosas propuestas didácticas que desde la Historia de la Educación y el museismo pedagógico contribuyan a visibilizar y a socializar una muestra importante de la memoria y el patrimonio de la educación.

\footnotetext{
9 A principios de 2020, el número de miembros que componen la sociedad asciende a más de 500 ciudades de 36 países y todos los continentes (África: 5 países/8 ciudades; América: 9 países/75 ciudades; Asia-Pacífico: 6 países/29 ciudades; Europa: 14 países/392 ciudades). Cfr. https://www.edcities.org/listado-de-las-ciudades-asociadas/

${ }_{10}$ Cfr. https://www.edcities.org/rece/

${ }^{11} L a s$ descripciones de estas experiencias pueden ser consultadas en los tres idiomas oficiales de la Asociación: español, francés e inglés. En el caso que nos ocupa, y por su estrecha relación con planteamientos patrimoniales e histórico educativos, sugerimos la lectura de las siguientes experiencias internacionales: a) La casa de las culturas urbanas. Dakar. Senegal; b) Makerspaces de las bibliotecas municipales. Espoo. Finlandia; c) Memoria y vida. San Pablo. Brasil; d) Infancia, arte y lenguajes. Lyon. Francia; e) La escuela adopta un monumento. Turín. Italia; f) Museo a cielo abierto. Godoy Cruz. Argentina. Cfr. https://www.edcities.org/banco-de-experiencias/
} 
La ciudad como espacio de ciudadanía activa y convivencial (ANDER-EGG, 2008), y como microcosmos que es, está llena de posibilidades para conocer mundos más amplios y aprender todo lo que no se puede enseñar en las instituciones escolares, pero que también forma parte de nuestra cultura y de nuestra manera de estar en la vida. Así, conscientes de que las personas carecen tanto de elementos descodificadores del patrimonio, como de fórmulas para interpretarlo y conocerlo, tenemos que entender que,

la formación de una ciudadanía de calidad mediante la educación dentro del marco de las ciudades educadoras, lleva aparejada la tarea de dotara los hombres y mujeres de aquellos instrumentos necesarios para que puedan comprender y sean capaces de explicar sus propios espacios urbanos, concebidos como grandes contenedores de patrimonio. (COMA; SANTACANA, 2010, p. 17)

A través de la Nueva Carta de Atenas, 2003, sobre la visión de las ciudades en el siglo XXI del Consejo Europeo de Urbanistas ${ }^{12}$, el Consejo Europeo de Urbanistas (ECTP) presentó una común y ampliamente consensuada visión sobre el futuro de las ciudades europeas, en las que se ponía de manifiesto la necesidad de conservar su riqueza y diversidad cultural -resultado de su larga historia-, que liga el pasado con el futuro a través del presente. Además, las responsabilidades de nuestras ciudades para con la producción, comunicación y divulgación de la ciencia, el conocimiento y la cultura, pasan por integrar un conjunto de acciones de formación, producción e interpretación, que contribuyen a su revalorización científica y cultural como agentes sociales y culturales. En definitiva,

la ciudad es hoy el núcleo fundamental en donde se materializan las relaciones humanas. Y es por ello que tenemos que aspirar a una ciudad que sea para todos/as; a una ciudad participativa, segura, saludable, productiva, innovadora, creativa, racional en sus movimientos y en sus accesos, inclusiva, accesible, [...] a una ciudad de la cultura. [...] se puede aprender a ser ciudadano/a a través de la transmisión de conocimientos y valores culturales. (DEL POZO, 2008, p. 26).

\footnotetext{
12 Carta de Atenas, (2003). Cfr. http://femp.femp.es/files/566-3-archivo/CARTA\%20de\%20a TENAS\%20version\%20final.pdf
} 


\section{El patrimonio histórico educativo como objeto de estudio y fragmento de un pasado escolar compartido}

Son muchos los estudios y proyectos transversales que en los últimos quince años, especialmente, han visto la luz para poner de manifiesto el protagonismo y repercusión que ha tenido el patrimonio educativo en el quehacer investigador que viene desarrollando la comunidad científica internacional de historiadores/as de la educación de la actualidad (BOYER, 2011; ESCOLANO, 2010; LÓPEZ, 2013; MENEZES, 2016; MOGARRO, 2015; MORENO, 2015; POSSAMAI, 2012; 2018; RUíz, 2010;). De esta forma, López (2013, p. 18), nos recuerda que los/as profesionales de la Historia de la Educación "han reorientado su dedicación hacia el funcionamiento interno de la escuela, poniendo de relieve que ésta puede y debe entenderse como un espacio social que se construye con una cultura propia." El mismo historiador de la educación viene a reseñar que,

el creciente y renovado interés por la recuperación, conservación, estudio, difusión y uso didáctico del patrimonio escolar, así como el reciente impulso en la creación de museos pedagógicos y exposiciones, a modo de archivos vivos de la memoria, constituyen -sin duda- uno de los frutos principales de esa conjunción de intereses entre la cultura escolar y el ámbito docente e investigador de la Historia de la Escuela. (LÓPEZ, 2013, p. 32)

El patrimonio es una construcción social y un fenómeno dinámico e integrador, que es preciso entenderlo como fuente para el intercambio de conocimientos. Si lo concebimos como un fragmento cultural de un pasado compartido (SANTACANA; HERNÁNDEZ, 2006), tenemos que referirnos también al conjunto de formas del pasado a las que reconocemos y valoramos en el presente. El patrimonio como parte visible de la historia, se convierte a su vez en herencia histórica y en historicidad evidenciada. Así, cuando hablamos de patrimonio cultural, tenemos que considerar que: a) Es parte de la riqueza de toda la sociedad; b) Hace referencia a recursos difícilmente renovables; c) Contribuye a la configuración de la herencia colectiva de una ciudad; d) Aporta identidad, origen y continuidad a nuestras ciudades; y e) Merece ser preservado de destrucciones espontáneas injustificadas e indiscriminadas. Y en este sentido, Freitas nos recuerda que, 
patrimonio y el proceso de selección de un bien cultural, de naturaleza material o inmaterial, legitimado por un grupo de individuos o una sociedad, a través de la interiorización del conocimiento, del entendimiento, de la apropiación y del pertenecimiento de ese bien, resultando en su opinión como herencia cultural, a ser valorizado y preservado por la generación presente, buscando su perpetuación por las generaciones futuras. (FREITAS, 2009, p. 6, tradução nossa) ${ }^{13}$

Como seres históricos, tenemos la obligación de tener en nuestra mente el pasado de la Humanidad. Y, como ciudadanos/as tenemos la obligación moral de socializar con el patrimonio a través de la educación (GUZMÁN, 2016). La sociedad sigue teniendo pendiente el reto de aprender a sentirlo como propio, y junto a ello, le corresponde aprender a desarrollar el sentimiento del compromiso personal para con nuestro legado cultural. El patrimonio a su vez tiene una función social que trasciende la de la conservación de elementos de cultura especialmente valiosos o significativos.

Si la historia se ocupa de todos los avatares del ser humano en el gigantesco ámbito del pasado, estamos en disposición de asumir que histórico es todo cuanto posee la huella del ser humano. El compromiso de la ciudadanía con la historia del tiempo escolar, pone de manifiesto que el patrimonio histórico educativo no es solamente territorio del historiador/a de la educación. Se trata de un patrimonio colectivo, que nos traspasa a todos/as, de un fragmento del pasado que forma también parte de nuestro presente. En el estudio del patrimonio educativo, no solamente nos interesa recuperar objetos escolares (patrimonio material), sino también la memoria de los sujetos, los testimonios vivos (patrimonio inmaterial). Además de la parte tangible y visible de la Historia de la Educación, es necesario aprender a buscar y encontrar el recuerdo en conversaciones sosegadas con los textos de la historia, debiéndose aspirar en consecuencia a la interpretación de las voces del pasado. Objetos, pero también escritos y voces ligadas al mundo de la escuela, constituyen un patrimonio histórico educativo muy valioso e importante, que hay que salvar, aprovechar y

\footnotetext{
${ }^{3}$ patrimonio e o proceso de seleçao de un bem cultural, de naturaleza material ouimaterial, legitimado por um grupo de individuos ouumasociedade, através da interiorizaçao do conhecimento, do entendimento, da apropiaçao e do pertencimentodessebem, resultando emsuaaleiçao como herença cultural, a ser valorizado e preservado pela geraçao presente, visando suaperpetuaçao pelas geraçoes futuras. (FREITAS, 2009, p. 6).
} 
dar a conocer. En este sentido, las recientes y acertadas palabras de Mayordomo, lo expresa con claridad:

Las huellas o muestras que conservamos de nuestro pasado educativo son preciados bienes culturales que nos transmiten un patrimonio o herencia; sin duda nos permiten comprender mejor bastantes aspectos importantes del mismo. Podemos hacerlo por medio de diversas materialidades que perduran, pero también a través de voces y escritos que vienen de aquel tiempo pretérito, o que estamos en condiciones de obtener, en la actualidad, desde la palabra viva de actores y/o testigos del mismo. (MAYORDOMO, 2020, p. 3)

De esta forma, los elementos que conforman el patrimonio educativo, se convierten para el/la historiador/a de la educación en fuentes y testimonios de un pasado que nos ayuda a entender e interpretar el ayer y el presente de la educación. Es así que tal y como señala López, (2013, p. 34), desentrañar la cultura escolar a partir de la interpretación de la cultura material e inmaterial "es el gran objetivo investigador del patrimonio educativo." Ante estos planteamientos, la conservación del legado patrimonial educativo va a adquirir su mayor sentido, en la medida en que seamos capaces de entender y compartir una serie de cuestiones fundamentales como las siguientes: a) En la actualidad, tenemos una deuda y un deber moral para con nuestro pasado educativo; b) El patrimonio educativo se presenta como testimonio vivo y visible del pasado educacional; c) Es preciso manifestar el respeto que debemos hacia el acontecer pedagógico de las generaciones que nos han precedido; d) Tenemos la responsabilidad de entregar el testigo de nuestra historicidad pedagógica a quienes nos sucedan; e) Al preservar el patrimonio educativo, las generaciones actuales estamos sirviendo de puente y conexión entre pasado, presente y futuro.

La recreación etnológica del patrimonio escolar (ESCOLANO, 2010), en definitiva, no sólo supone un placer nostálgico al abrir la memoria al recuerdo de tiempos infantiles, sino que también, tal y como argumenta López (2013, p. 33), "brinda la posibilidad de aproximarse al análisis de los códigos pedagógicos de la cultura escolar de cada época histórica”. El patrimonio histórico educativo es un bien que debe ser mostrado públicamente para que pueda ser observado y 
examinado por todos/as. Salvaguardar, construir y comunicar los valores de la memoria educativa no es un mero rictus nostálgico; es más si cabe, una actitud de responsabilidad pública. Y en este momento, es necesario reivindicar la incorporación del patrimonio educativo a la conceptualización del denominado patrimonio cultural, ampliándose así la reduccionista exclusivización centrada desde antaño en el orden artístico y monumental, más concretamente.

Por todo ello, si nos preguntamos cuáles han de ser los principales desafíos a los que deben enfrentarse los estudiosos del patrimonio educativo en el ámbito de la Historia de la Educación, podemos apuntar al menos dos, planteados por Silva recientemente:

[...] El primero está en la problemática de los sujetos y sus lugares. Explorar las ciudades, los museos y las escuelas debe servir también para comprender las luchas simbólicas instituidas en las historias contadas, en los propios modos de contarlas, en los sujetos representados y en los modos de representación. Es en esa dimensión multifacetada que nos parece interesante explorar el patrimonio como fuente $\mathrm{y}$, al mismo tiempo, como objeto histórico. El segundo desafío está en la necesidad de estar atentos a otros espacios/experiencias que constituyen la formación de los sujetos, para además de la escuela, tensionando las relaciones que se establecen entre esas diferentes instancias educativas. (SILVA, 2019, p. 439) $)^{14}$.

Desligar el estudio del patrimonio educativo de los museos pedagógicos (ÁLVAREZ, 2016), entendidos como espacio de cultura y de enseñanzaaprendizaje (FERNÁNDEZ, 2003), resulta insostenible, sobre todo si queremos reconocer el papel que la universidad está desarrollando en lo que atañe a la creación de museos y/o centros de memoria e interpretación del patrimonio, seminarios de cultura escolar, aulas de memoria pedagógica, exposiciones monográficas de Historia de la Educación, etc. Así, en este trabajo en concreto nos centraremos a continuación en explorar las posibilidades que tienen los museos pedagógicos universitarios en aras de contribuir a la difusión y

\footnotetext{
14 [...] O primeiro está na problemática dos sujeitos e seus lugares. Desbravar as cidades, os museus e as escolas debe servir também para compreendermos as lutas simbólicas instituídas nas histórias contadas, nos próprios modos de contá-las, nos sujeitos representados e nos modos de representação. É nessa dimensão multifacetada que nos parece interessante explorar o patrimônio como fonte e, aomesmo tempo, como objeto histórico. O segundo desafio está na necessidade de atentarmos para outrosespaços/experiências que constituem a formação dos sujeitos, para além da escola, tensionando as relações que se instauram entre essas diferentes instâncias educativas. (SILVA, 2019, p. 439).
} 
divulgación del patrimonio histórico educativo a toda la sociedad. La exploración de estas posibilidades no ha de ser considerada ciencia ficción, sino más bien todo lo contrario, ya que, en cierto sentido, se trata de hacer arqueología de museo educativa desde un punto vista didáctico.

Los museos pedagógicos han llegado a la universidad para quedarse ${ }^{15}$. Amplia ha sido la proliferación, ampliación o promoción que estas instituciones han experimentado en los últimos años (MEDA, 2010; RABAZAS; RAMOS, 2016; RUÍZ, 2006), y en este sentido, no necesitan tanto cambiar de rostro y apariencia física, como adaptarse a nuevas formas de relación con el público y a nuevos retos, prácticas y acciones que acerquen la Historia de la Educación de una manera más disruptiva y creativamente a estudiantes de Magisterio y Pedagogía, en particular, y a la sociedad en general. Y con respecto a esto, la utilización de las tecnologías de la información y la comunicación van a facilitar el desarrollo de aprendizajes directos (en el propio museo) e indirectos (a través de la red) ${ }^{16}$, ligados al estudio del patrimonio educativo y la memoria escolar. El museo pedagógico universitario está obligado a mostrar su capacidad para estructurar su acción didáctica y divulgativa en el contexto institucional en el que se ha gestado, y en que tendrá que habitar en el futuro contribuyendo a la transferencia del conocimiento patrimonial histórico educativo. Ahora, los museos pedagógicos en la universidad se mueven a caballo entre lo que han conseguido hacer, lo que son y lo que pueden llegar a ser. El reto que hoy se hace presente pasa por hacer posible que estos espacios de memoria llenos de riqueza patrimonial histórico educativa, ni se deterioren, ni mueran didácticamente hablando (GUZMÁN, 2016), ni prescindan de la necesidad de ofrecer lo que tienen y está en sus manos, a toda la ciudadanía.

\footnotetext{
${ }^{15}$ En el caso de España, que es el que nos ocupa en este trabajo, destáquese que desde 1989 hasta nuestros días, se han erigido 9 Museos Pedagógicos en contextos universitarios. Desde ese año, con la fundación del Museo Laboratorio de Historia de la Educación M. Bartolomé Cossío, 8 más han continuado la senda del mencionado, hasta llegar a 2016 con la fundación del Museo de la Educación de la Universidad del País Vasco, que ha sido el último en sumarse a este proyecto comunitario. Se recomienda conocer el trabajo que realiza este último a través de Dávila y Naya (2017).

16 Respecto a esto, sugerimos la consulta en patrimonioeducativo.es, un Espacio Virtual de Aprendizaje para la Didáctica del Patrimonio Histórico Educativo. Cfr. www.patrimonioeducativo.es
} 


\section{Universidades y museos pedagógicos como gestores de acción} cultural en la comunicación del patrimonio de la educación

No cabe duda de que la conformación del mundo en el que vivimos, se ajusta en parte a la producción de conocimientos en los que interactúan las Ciencias Sociales. Y si estas Ciencias se nutren de cuestiones ligadas a la sociedad, en general, resulta natural pensar que las mismas podrán mostrarse receptivas a sus logros, mientras sean capaces de desarrollarlos de manera atractiva. La selección adecuada de contenidos y experiencias que merecen llegar a la sociedad de forma inteligible, asequible, concisa, dinámica y clara, es un reto a renovar constantemente en el ámbito de las Ciencias Sociales (QUIÑÓNEZ, 2011), sobre todo si nuestra intención se centra en facilitar la divulgación del conocimiento en nuestras ciudades y en popularizar la comunicación de la ciencia (PERRAULT, 2013).

Las ciudades y con ellas las universidades como instituciones educativas de alto rango, tienen responsabilidades compartidas en la construcción del mundo actual, y juntas han de activarse para contribuir al desarrollo de nuestra identidad cultural. La universidad -entendida como fábrica de la cultura-, y que invierte en creatividad cultural, contribuye a la mejora y a la transformación de la sociedad. Se convierte en laboratorio cultural que puede ayudar a configurar identidades y el sentido de pertenencia a una comunidad. Las universidades son responsables de gran parte del conocimiento que se genera en la mayoría de todos los países del mundo. Y en este sentido, les corresponde desarrollar un compromiso importante con relación a la divulgación, que se concreta en "difundir entre la sociedad los resultados de su investigación", tal y como argumentan Lascurain y Sanz (2009, p. 511). Aspecto este que corre normalmente a cargo de las Oficinas de Transferencia de Resultados de Investigación (OTRI)17, concebidas como estructuras que fomentan la cooperación en actividades de I+D entre investigadores y empresas y facilitan la tarea de comunicación institucional y de transmisión de conocimientos científicos al gran público.

\footnotetext{
7 Cfr. Orden del 16 de febrero de 1996 reguladora del registro de oficinas de transferencia de resultados de investigación en la Comisión Interministerial de Ciencia y Tecnología. BOE, no 47, del 23 de febrero de 1996 http://www.ciencia.gob.es/portal/site/MICINN/menuitem.7eeac5cd345b4f34f09dfd1001432ea0/ ?vgnextoid=14ab3a1375bb4410VgnVCM1000001d04140aRCRD
} 
El Programa Horizon 202018, encargado de financiar proyectos de investigación e innovación de diversas áreas temáticas en el contexto europeo, ha incluido una nueva variable en los proyectos de investigación, como es la exigencia y apuesta por la comunicación y la diseminación, de cara a extender a la sociedad los beneficios de los proyectos de I+D financiados con fondos públicos. Comunicar, más que informar, conlleva demostrar cómo nuestra I+D+i contribuye a alcanzar logros y resultados transferibles e influyentes en el bienestar de la ciudadanía.

La comunicación y difusión de los resultados de la investigación se suele concretar normalmente en la realización de informes y artículos accesibles para todo el público, en parte a través de libros, informes, artículos científicos, compilaciones, catálogos, reseñas, textos periodísticos, etc., así como en la comunicación a través de la web. Sin embargo, más allá de esto, necesitamos diseñar estrategias y planes comunicativos (ESCOBAR-ORTíZ; RINCÓN-ÁLVAREZ, 2019), que nos permitan que el conocimiento generado por las Ciencias Sociales termine influyendo en el día a día de los ciudadanos/as.

En las dos últimas décadas, particularmente, el quehacer de la Historia de la Educación ha puesto un interés especial en investigar, estudiar y conservar el patrimonio educativo para facilitar su comunicación, exposición, difusión, transferencia e internacionalización. En el caso de España, el memorial de trabajo coordinado por la Sociedad Española para el Estudio del Patrimonio Histórico Educativo (SEPHE) 19 desde el año 2004, y recogido en sus "Boletines SEPHE”20, lo pone amplia y exitosamente de manifiesto. Al respecto, en Historia de la Educación, tal y como nos sugieren Lascurain y Sanz (2009, p. 509), la comunicación, y con ella, la divulgación, "no puede hacerse bajo demanda, sino que necesita de una actitud proactiva para despertar el interés social por la ciencia." La Historia de la Educación, además de llegar a los que muestran interés por ella, tiene que plantearse también llegar a nuevos clientes y agentes sociales.

Tal como la ciencia y la sociedad cambian, también le corresponde evolucionar a la comunicación de la cultura científica; y justamente, los museos

\footnotetext{
${ }^{18} \mathrm{Cfr}$. https://eshorizonte2020.es/

${ }^{19} \mathrm{Cfr}$. https://sephe.org/

${ }^{20}$ Un total de 13 Boletines Informativos "BISEPHE" pueden consultarse en: https://sephe.org/bisephe/
} 
forman y formarán parte esencial de la transformación de la ciencia en cultura (ARIÑO, 2019). Por ello, la Historia de la Educación ha encontrado en los museos pedagógicos (ÁLVAREZ, 2016), un potente pilar de comunicación del patrimonio educativo; y con ello, las propias universidades, creando los suyos propios ${ }^{21}$.

Actualmente, el espacio por excelencia de exhibición del patrimonio histórico educativo, es sin duda, el museo pedagógico. Así pues, reconociendo que la pedagogía es y debe ser el ente sustancial de esta tipología de museos (GÓMEZ, 2003), González (2000, p.12), nos recuerda que un museo pedagógico debe ser "un lugar de memoria que integre como objetivos fundamentales la custodia, conservación, interpretación y difusión de los valores de una sociedad, ideas, ideología, que transmite a través de la educación." Estos museos, son concebidos como "espacios físicos y simbólicos, lugares propicios para hacer historia, para recuperar las voces -y a veces los susurros- que se han depositado en objetos, manuales escolares, en espacios, en los símbolos que presidieron el tiempo escolar" (JUAN, 2008, p. 17). No son precisamente lugares para la nostalgia en sí misma, sino que como argumenta Juan:

son espacios en los que se mezclan los recuerdos escolares con los recuerdos de la infancia; espacios para la memoria recuperada, una memoria que permita a la sociedad reflexionar sobre lo que la escuela ha sido, entender el presente y soñar el futuro de la escuela y de la educación. (JUAN, 2008, p. 18)

Con ello, nos referimos a centros de interpretación de la cultura histórico educativa, dirigidos a toda la sociedad, que ofrecen conocimientos, información, oportunidades para emocionarnos, experiencias didácticas y posibilidades para garantizar el estudio, conservación, exposición, difusión e interpretación del patrimonio de la educación (ÁLVAREZ, 2016). En la misma línea, Ruiz establece que el museo pedagógico es una institución en la que el almacenamiento, la visión estática y la espera del visitante anónimo han sido superados. Se trata pues, de una institución que ha dejado de ser mausoleo

\footnotetext{
${ }^{21}$ En el caso de España destacan los siguientes museos pedagógicos universitarios: Museo Laboratorio de Historia de la Educación "Manuel B. Cossío" de la Universidad Complutense de Madrid (1989); Museo de la Educación de la Universidad de la Laguna (1999); Centro de Estudios sobre la Memoria Educativa de la Universidad de Murcia (CEME) (2009); Centro Museo Pedagógico de la Universidad de Salamanca (CEMUPE) (2010); Seminario-Museo de Historia de la Escuela de la Universidad de Valencia (2010); Museo Pedagógico de la Universidad de Huelva (2011); Museo Pedagógico de la Facultad de Ciencias de la Educación de la Universidad de Sevilla (2012); Museo de la Educación de la Universidad del País Vasco (2016) (ÁLVAREZ; PAYÀ, 2015).
} 
para convertirse en algo vivo, en un proyecto continuo, en una empresa democrática y científica, que tiene mucho que ofrecer a los pueblos y gentes de su alrededor y no sólo a pedagogos que se consideran autoridades inamovibles o a eruditos historiadores a la violeta. (RUIZ, 2006, p. 283)

Martín y Ramos (2008, p. 71), hacen hincapié también por otra parte en que los museos pedagógicos "brindan la posibilidad de regresar a los espacios de nuestra escuela, de recordar lo olvidado, de reinterpretar con nuevas claves aquello que vivimos, sentimos o aprendimos, enriqueciendo nuestro patrimonio educativo." Junto a ello, y considerando las aportaciones de Meda (2010), hemos de entender que el museo pedagógico, además de ser el lugar de conservación por excelencia del patrimonio educativo, es también un entorno de aprendizaje real, dentro del cual es posible promover la formación y la actualización pedagógica de los futuros docentes. Así, establece que este museo debe ser un lugar para:

[...] la divulgazione della storia dell'educazione, sia per gli studenti de lle scuole di diverso ordine e grado attraverso attività didattiche, esposizionie visite guidate, sia per i professionisti della scuola e dell'educazione attraverso incontri e seminarî rivolti a lla valorizzazione dei beni culturali della scuola. (MEDA, 2010, p. 499)

El museo, en su labor y empeño por difundir el patrimonio de la educación, y fiel al desempeño de esta tarea, ha de generar una visión crítica del pasado de la educación, que contribuya a la formación de la identidad y a la transformación social de la ciudadanía. Que es la función y compromiso social de los museos pedagógicos. Al museo también se le considera una importante herramienta pedagógica de carácter reflexivo, ya que establece, tanto en el tiempo como en el espacio, una constante interacción entre los procesos, productos y prácticas de sociedades pasadas y presentes.

El museo pedagógico transmite un discurso del pasado que en forma diferida, es así mismo un discurso sobre el presente de la educación, en el cual la forma de exponer el patrimonio resulta clave para su interpretación y transformación. De esta forma, meditar sobre sus potencialidades educativas y divulgativas desde una perspectiva crítica, nos ha de llevar a considerar la labor museológica, museográfica y de difusión cultural que desarrollamos desde la Historia de la Educación, y a plantear qué tipología de museos queremos tanto 
hoy como en el futuro. Los museos pedagógicos universitarios se han convertido en laboratorios ciudadanos para el estudio de la cultura escolar y el patrimonio histórico educativo y en espacios culturales de innovación histórica educativa universitaria (BORDIGNON, 2017). No obstante, necesitamos museos pedagógicos más sociales, en permanente diálogo con la comunidad universitaria, con el fin de que ésta, a través de su patrimonio histórico educativo, pueda reflexionar crítica y subjetivamente acerca de la realidad de la cual forma parte (PUEBLA, 2013).

Con la efervescencia de los museos pedagógicos en los últimos quince años, hemos participado en el diseño de un nuevo modelo de divulgación didáctica emergente en lo que atañe al estudio, difusión y puesta en valor del conocimiento patrimonial histórico educativo. Con ello, hemos apostado por fundar una nueva pedagogía de la narración histórico educativa (DAMIANO, 2004), tomando como base la reconstrucción hermenéutica de las culturas escolares a través del tiempo. Y través de ella, nos hemos interesado por la dimensión diacrónica del conocer y del saber enseñar a través de la narración, la representación, la reformulación, la reconstrucción de hechos, pensamientos, ideas, etc., relacionadas con el ayer de la educación. Mirar al pasado de las instituciones educativas es un ejercicio de explicación en el presente, de salvaguarda en relación con el pasado y de prospectiva en cuanto al futuro. De esta forma, a través de la reconstrucción del pasado escolar desde el presente, estamos construyendo continuas metáforas imaginadas, en la que escenarios, objetos, actores e inmaterialidades de la escuela se convierten en agentes patrimoniales de difusión cultural.

En el intento de comunicar parte del conocimiento histórico educativo que se genera en el ámbito de la Historia de la Educación, el museo pedagógico universitario se presenta como una completa e ilustrada lección histórico educativa, cuyo conocimiento debemos transmitir y perpetuar entre los individuos. Y esto, no siempre se consigue mediante la enseñanza reglada, por eso es muy necesario hacer de este museo un instrumento de carácter no formal que contribuya a ello. Igualmente, le corresponde esforzarse también por convertirse en un lugar turístico y para el disfrute de la ciudadanía, en un espacio 
de encuentro y reflexión sobre aquellos asuntos histórico educativos y pedagógicos que puedan resultar del interés de la sociedad. Justamente, esta utilidad del museo como objeto cultural y como esencia de las personas y al servicio de ellas, es la que va a garantizar la permanencia y el sentido de los museos pedagógicos en nuestras Universidades. En esta línea, de acuerdo con García (2020), a los museos pedagógicos universitarios les va a corresponder ejercer la vocación de mostrar a la sociedad los tesoros materiales e inmateriales más preciados de la educación. En ese sentido, la voluntad de seguir construyendo en torno a la cultura histórico educativa y comunicándola a la ciudadanía, ha de permanecer activa. Estos museos, como referencia y testimonio de un patrimonio cultural educativo que nos pertenece, tienen que convertirse en un espejo en el que las sociedades puedan buscar su reflejo y su identidad personal. Y al respecto, no cabe duda de que si queremos comunicar de verdad, el museo como intérprete del patrimonio educativo, ha de posibilitar un equilibrio entre la dimensión cognitiva, afectiva y social del sujeto.

\section{El reto de la divulgación científica en el caso del Museo Pedagógico de la Facultad de Ciencias de la Educación de la Universidad de Sevilla: formas, acciones y actividades}

La Unión Europea entiende como crucial el favorecer experiencias que desarrollen el pensamiento crítico y que la ciudadanía valore la ciencia como parte del progreso. El auge de la divulgación científica en Europa (ALARCÓN, 2013), ligado al papel y función social que en esta tarea están desarrollando las Universidades (PAREJO, MARTíN; VIVAS, 2017; VIVAS, PAREJO; MARTÍN, 2018), ponen de manifiesto que la divulgación también es ciencia y que la divulgación también es educación. Según señala Mendizábal (2016, p. 1), la divulgación "es un mecanismo ideal para hacer llegar a la población el conocimiento, sin las complicaciones técnicas de cada ciencia, pero manteniendo la esencia del saber adquirido." Y la divulgación científica ha de entenderse, tal y como apunta Escobar-Ortíz (2018, p. 138), como "una forma de comunicación pública de la ciencia." Si asumimos que la divulgación es también una necesidad educativa legítima, tenemos que reconocer así mismo, que es una herramienta para la educación, en al menos, las siguientes acepciones: a) Como vía de promoción de 
vocaciones científicas; b) Como vía de actualización científica para el alumnado y para docentes implicados en acercar la ciencia a sus estudiantes; c) Como instrumento para contribuir al desarrollo de una educación a lo largo de toda la vida; y d) Como medio para transmitir a la sociedad con claridad y con rigor una imagen no distorsionada de los aportes y avances de la ciencia, sin caer en la trivialización (MEDINA, 2012).

En la actualidad, el reto de hacer divulgación científica desde las universidades, supone una responsabilidad de la que no podemos prescindir. En estos momentos, uno de los mayores desafíos a la hora de organizar actividades de divulgación científica o comunicación social de la ciencia se centra en elegir los formatos más adecuados, empatizar con el público al que nos queremos dirigir y conocer el camino para llevar a término una idea. Al respecto, resulta destacable el papel que ejerce la European Science Engagement Platform, la primera Plataforma Europea de Divulgación de la Ciencia; una iniciativa de la European Science Engagement Association (EUSEA), encargada de servir a la comunidad científica y de ayudarla a la hora de encontrar inspiración, recursos, métodos y herramientas para llevar a cabo actividades de participación de carácter interactivo y orientadas al diálogo en diversos contextos institucionales y nacionales. Este recurso está particularmente destinado a las personas que tienen interés por poner en marcha actividades de divulgación de la ciencia, y de manera particular, a la comunidad divulgadora y educativa y a comunicadores científicos, con la intención de reunir en un mismo espacio, una serie de formatos inspiradores e innovadores para acercar la ciencia a la ciudadanía ${ }^{22}$. Por otra parte, también es destacable el portal de divulgación científica TheConversation ${ }^{23}$, una plataforma digital de carácter independiente que se centra en el análisis de la actualidad científica mediante artículos refrendados por profesores universitarios y especialistas de centros superiores e institutos de

\footnotetext{
22 Esta nueva herramienta, pionera en el ámbito europeo, ofrece una interesante y completa panorámica de los diferentes formatos de divulgación existentes, desde festivales, experimentos, rutas, competiciones, campamentos, cafés científicos, etc. El usuario designa el objetivo que persigue y el tipo de público al que se desea hacer llegar la actividad, y la Plataforma te ofrece una selección de los formatos más adecuados y oportunos. Así mismo, detalla las estrategias, los objetivos, las recomendaciones, los tipos de público y las herramientas que se han de tener en cuenta para poner en marcha un proyecto de divulgación. Cfr. https://eusea.info/platform/

${ }^{23} \mathrm{Cfr}$. https://theconversation.com/es
} 
Museos pedagógicos universitarios en ciudades educadoras del tiempo presente: divulgación del patrimonio histórico educativo

Pablo Álvarez Domínguez

investigación. La plataforma, concebida como una gran red mundial de divulgación del conocimiento, contribuye a compartir con el gran público investigaciones y conocimientos de una manera más accesible.

La divulgación científica realizada desde los museos pedagógicos universitarios conlleva que el/la divulgador/a científico/a ponga su empeño en trasladar a la sociedad el conocimiento creado a través de la Historia de la Educación, mediante un lenguaje "traducido" para la ciudadanía. Y en esta tarea, podemos contar con las oficinas de información científicas creadas por las universidades (LASCURAIN; SANZ, 2009), o con otras instituciones públicas o privadas, como puede ser el caso de la Fundación Descubre ${ }^{24}$, en la Comunidad Autónoma de Andalucía (España), por ejemplo. En esta línea, resulta reseñable además el papel que ejerce la Red Ibero-americana de Comunicación y Divulgación Científica ${ }^{25}$, que tiene como objetivo principal incrementar el volumen de información relativa a la ciencia y la tecnología que se encuentra disponible para la sociedad, mejorando la cultura científica de los ciudadanos y fomentando la transmisión de un acervo científico.

La divulgación en sí misma contribuye a comprender los desafíos que enfrenta la sociedad y sus posibles soluciones, a través de 3 funciones básicas que se refieren a informar, explicar y facilitar la comprensión del conocimiento (CALVO, 2006).En lo que atañe al caso del Museo Pedagógico de la Facultad de Ciencias de la Educación de la Universidad de Sevilla ${ }^{26}$,esta triple responsabilidad se desarrolla en los siguientes términos: a) Informar al público sobre la existencia del museo pedagógico, entendido como producto y escenario cultural para el encuentro de la ciudadanía con el patrimonio educativo; b) Explicar-tomando

\footnotetext{
${ }^{24}$ En este sentido, merece especial atención señalar el papel que desarrolla en Andalucía la Fundación Descubre. Una institución privada sin fines de lucro (2010), impulsada por la Consejería de Economía, Conocimiento, Empresas y Universidad de la Junta de Andalucía. Su patronato está formado por 22 instituciones de avalado prestigio en investigación y divulgación de la región andaluza: universidades, centros de investigación y divulgación, asociaciones, etc. Su misión se centra en el fomento del conocimiento científico en la ciudadanía andaluza mediante la organización, coordinación e impulso de iniciativas relacionadas con la ciencia. Con el objeto de convertirse en un punto de encuentro entre ciencia, sociedad y agentes de divulgación, la Fundación se plantea entre otros objetivos: a) Impulsar la divulgación del conocimiento estableciendo cauces para la difusión de la ciencia y la innovación a la sociedad; y b) Responder a los nuevos retos y necesidades de la sociedad y de la comunidad divulgadora andaluza. Cfr. https://fundaciondescubre.es/la-fundacion/

${ }^{25}$ Cfr. https://www.oei.es/historico/comunicacionydivulgacion/index.php

${ }^{26} \mathrm{Cfr}$. http://institucional.us.es/museopedagogia/
} 
como referencia principal la cultura material e inmaterial de la escuela y la memoria de la educación-, los principales acontecimientos que han ayudado a conformar la Historia de la Educación española; y, c) Facilitar oportunidades presenciales y virtuales para que la ciudadanía comprenda a través de actividades y recursos, el conjunto de contenidos histórico educativos expresados en el planteamiento museológico del museo. En este caso en el que nos centramos, el museo trata de hacer siempre un esfuerzo ímprobo por completar sus funciones museológica y museográfica con el desarrollo de una función difusora, centrada en aumentar la dimensión expositiva y respondiendo a los intereses específicos de distintos tipos de públicos. De esta forma, trabajamos conscientemente por "cuidar informativa y publicitariamente" la imagen del propio museo, tal y como indican Alonso y García (2010, p. 212).

Raichvarg y Jacques (1992), proponen cuatro formas de divulgación científica (tabla 1) definidas en función de la tipología de lenguaje que en ellas imperan. Así, podemos destacar:

a) La divulgación en tres dimensiones: nos referimos a museos, exposiciones, gabinetes de historia, laboratorios científicos, etc.; b) La escritura: se trata del código que se utiliza cuando se quiere realizar una actividad divulgativa a partir de publicaciones en libros, revistas, diarios, dossiers, periódicos, enciclopedias, etc.; c) La palabra: hace referencia al lenguaje que se materializa a través de impartición de conferencias, seminarios, programas de radio, teatro científico, cursos de extensión universitaria, poesía, monólogos científicos, etc.; y d) La imagen: se refiere a las representaciones que manifiestan la experiencia visual de un objeto real o imaginario mediante documentales, dibujos, cine científico, infografías, sistemas multimedia, etc. Además de estas formas de hacer divulgación científica (BELENGUER, 2003), existen otras propuestas ligadas, por ejemplo, a ferias científicas y festivales de divulgación; rutas didácticas y paseos científicos; eventos conmemorativos; espectáculos; etc. 
Tabla 1 - Formas de divulgación científica.

\begin{tabular}{|c|c|}
\hline $\begin{array}{c}\text { Formas de } \\
\text { divulgación } \\
\text { científica }\end{array}$ & Acciones/actividades \\
\hline $\begin{array}{l}\text { a) } \\
\text { Divulgación } \\
\text { en tres } \\
\text { dimensiones }\end{array}$ & $\begin{array}{l}\text { Museos. } \\
\text { Exposiciones. } \\
\text { Gabinetes de historia. } \\
\text { Laboratorios científicos. } \\
\text { Museos en la calle. }\end{array}$ \\
\hline $\begin{array}{l}\text { b) A través } \\
\text { de la } \\
\text { escritura }\end{array}$ & $\begin{array}{l}\text { Libros. } \\
\text { Revistas científicas y de divulgación. } \\
\text { Diarios. } \\
\text { Dossiers. } \\
\text { Enciclopedias. } \\
\text { Reportajes de prensa. } \\
\text { Reseñas. } \\
\text { Memoriales. } \\
\text { Cómics. } \\
\text { Cuentos. }\end{array}$ \\
\hline $\begin{array}{l}\text { c) A través } \\
\text { de la } \\
\text { palabra }\end{array}$ & $\begin{array}{l}\text { Conferencias. } \\
\text { Jornadas, seminarios y workshops. } \\
\text { Programas de radio. } \\
\text { Teatro científico. } \\
\text { Cursos de extensión universitaria. } \\
\text { Poesía. } \\
\text { Monólogos científicos. } \\
\text { Charlas y cafés en pubs. } \\
\text { Parlamentos estudiantiles. } \\
\text { Debates. Science and you (diálogos con científicos) } \\
\text { Concursos de relatos, guiones, poemas, etc. } \\
\text { Encuentros intergeneracionales orales entre abuelos/as-nietos/as. } \\
\text { Representaciones teatrales. }\end{array}$ \\
\hline $\begin{array}{l}\text { d) A través } \\
\text { de la } \\
\text { imagen }\end{array}$ & $\begin{array}{l}\text { Documentales. } \\
\text { Dibujos animados. } \\
\text { Cine científico. } \\
\text { Fotografías e infografías. } \\
\text { Sistemas multimedia. } \\
\text { Programas de televisión. } \\
\text { Reportajes. } \\
\text { Videos. } \\
\text { Grabaciones de entrevistas, testimonios. } \\
\text { Performances científicas. } \\
\text { Concursos de dibujo y pintura, de carteles científicos. } \\
\text { Uso de las nuevas tecnologías y medios interactivos, Internet, } \\
\text { experiencias en 3D, audioguías en 3D y/o Realidad Virtual. } \\
\text { Museos virtuales, páginas web interactivas; APP especializadas y } \\
\text { códigos QR. }\end{array}$ \\
\hline e) Otras & $\begin{array}{l}\text { Ferias científicas y festivales de divulgación, jornadas de puertas } \\
\text { abiertas. } \\
\text { Talleres didácticos y de diseño. } \\
\text { Celebración de eventos conmemorativos. } \\
\text { Campamentos científicos, experimentos masivos, competiciones y } \\
\text { olimpiadas científicas. }\end{array}$ \\
\hline
\end{tabular}




\begin{tabular}{|l|l|}
\hline Rutas y paseos científicos. Excursiones y campañas de sensibilización \\
(MindtheLab). \\
ScapeRooms y experiencias de gamificación. \\
SoapboxScience (Ciencia en la calle), rutas didácticas por el territorio \\
rural/urbano, yincanas. \\
Hackathons sociales (Resolución de problemas reales). \\
Disidencias rituales (someter propuestas e historias a desafíos) y \\
juegos de discusión (PlayDecideGame). \\
Walkshop (intercambios de escenarios). \\
Espacios Tinkering (Pensar con las manos). \\
Espectáculos de baile, danza científica, títeres, marionetas. \\
\hline
\end{tabular}

Fuente: Elaboración propia, 2020.

La transferencia de conocimiento en educación ha de ser un desafío estratégico para toda institución educativa (SANTOS, 2020). Y en base a lo cual, las actividades divulgativas mencionadas con anterioridad van a requerir dos esfuerzos fundamentales por parte de sus impulsores: por un lado, transformar estos hallazgos académicos en productos de interés para la sociedad en general - para lo cual resulta fundamental adaptarlos en forma y fondo a las inquietudes y conocimientos del público-; y, por otro, conseguir que estas actividades alcancen una cierta repercusión social (SOLANAS, MARTORELL; SERRA, 2013). Partiendo entonces de que las formas que puede adoptar el proceso de divulgación científica son múltiples, presentamos a continuación un análisis descriptivo de aquellas que en concreto ha asumido el Museo Pedagógico de la Facultad de Ciencias de la Educación de la Universidad de Sevilla desde su fundación en 2012, no sin dejar la puerta abierta a futuras investigaciones en perspectiva comparada que amplíen la muestra de estudio al conjunto de museos pedagógicos universitarios españoles a corto plazo, y extranjeros a largo plazo. Siguiendo con los parámetros planteados anteriormente, señalamos las más significativas en relación con los diferentes bloques de formas de divulgación que hemos apuntado:

\section{a) Divulgación en tres dimensiones}

Respecto a esto, se ha de destacar principalmente, el propio museo en sí mismo. Se trata de un lugar cultural y de interrelación con la Historia de la Educación, integrado en la segunda planta del edificio de la Facultad de Ciencias 
de la Educación de la Universidad de Sevilla ${ }^{27}$. El espacio del museo se concibe y utiliza como teatro de la memoria (ÁLVAREZ, REBOLLO; NÚÑEZ, 2016) y como recurso de divulgación científica que invita a los espectadores que lo visitan a convertirse en actores de su propio pasado educativo, a interactuar con la historia y la cultura, y a proyectar su imaginación histórica. En el reglamento del museo ${ }^{28}$, se hace constar expresamente que uno de sus principales objetivos en relación con el legado patrimonial educativo se concreta en "establecer cauces de información, difusión y extensión cultural para dar a conocer la importancia del patrimonio educativo". Y en este sentido el museo, a través de sus dos salas expositivas, principalmente, (una dedicada particularmente a la educación republicana y al periodo del nacionalcatolicismo en España, y otra a la Educación General Básica (EGB), con la Ley General de Educación de 1970), pone a disposición de la ciudadanía un escenario para la representación de la memoria escolar, cuya existencia se ha convertido en agente dinamizador de la Facultad, propiciando encuentros intergeneracionales y visitas de diferentes colectivos y agentes sociales. Junto a ello, es necesario destacar también las diferentes exposiciones temporales ${ }^{29}$ que el museo ha ido concibiendo progresivamente para deleite de sus visitantes. Exposiciones que además han sido cedidas en préstamo a otras agencias educativas, como centros de Educación Primaria o Secundaria, por ejemplo; lo que ha permitido que el conocimiento histórico educativo haya llegado a un público más amplio.

\section{b) Escritura}

En este sentido, tenemos que señalar que el equipo ejecutivo del museo ha realizado importantes esfuerzos por difundir y dar a conocer su patrimonio y su quehacer a través de múltiples publicaciones en formatos diversos. Así, existen diferentes trabajos ${ }^{30}$ de temáticas diversas publicados en libros; capítulos

\footnotetext{
${ }^{27}$ Cfr. http://institucional.us.es/museopedagogia/contacto/

${ }^{28} \mathrm{Cfr}$. http://institucional.us.es/museopedagogia/informacion/reglamento/

${ }^{29}$ En este sentido, destacamos a modo de ejemplo y por su éxito, dos exposiciones temporales ligadas al tema "Mujer e Historia de la Educación": a) "Aprendiendo a ser mujer en la España del siglo XX: una carrera de fondo" (2014) y b) "Mujeres de anuncio. Evolución de los modelos de identidad femenina en la publicidad española” (2015), ambas comisariadas por la profesora M. José Rebollo Espinosa.

30 Una parte importante de estos trabajos pueden consultarse en la página web del Museo Pedagógico. Cfr. http://institucional.us.es/museopedagogia/informacion/bibliografia/
} 
de libro; revistas científicas nacionales y extranjeras; revistas de divulgación; comunicaciones en actas de congresos, jornadas y seminarios; reportajes en prensa; cuentos infantiles online; etc. En este caso, procede destacar la publicación de la obra Los Museos Pedagógicos en España: entre la memoria y la creatividad (2006) ${ }^{31}$, coordinada por el secretario del Museo Pedagógico, y que se ha convertido en referencia bibliográfica de obligada consulta para el estudio del museísmo pedagógico. Así mismo, el museo pedagógico ha sido objeto de estudio, descripción y análisis en diferentes textos publicados al hilo de la celebración de eventos científicos, tanto de carácter nacional, como internacional. Otros documentos escritos como las memorias del museo, dípticos y trípticos informativos, fichas para autovisitas, guías para la autointerpretación del patrimonio, postales, carteles, textos en páginas web, etc., constituyen el variado elenco de formas de divulgación, que ligadas a lo escrito, ha adoptado el museo desde su fundación, en aras de acercar el patrimonio educativo a la sociedad.

\section{c) Palabra}

En lo que atañe a esta forma de divulgación, hemos de mencionar especialmente, la dimensión internacional que ha ido adquiriendo la labor divulgativa que se ha desarrollado desde el museo. Como ejemplo, hágase notar la presentación del museo en diferentes foros internacionales a través de la impartición de conferencias y/o ponencias en congresos, simposios, jornadas, seminarios y workshops celebrados en países tan dispares como España, Portugal, Italia, Francia, Argentina, Brasil, México, Uruguay o Cabo Verde, por citar algunos ejemplos. Particularmente significativo ha resultado además la impartición de 3 cursos de extensión universitaria ${ }^{32}$ dirigidos a toda la ciudadanía, en general. Hay que mencionar también la participación del museo en Cafés con

\footnotetext{
31 Cfr. https://www.diariodesevilla.es/vivirensevilla/museos-pedagogicos-Espana-BlibroB_o_ 1117088779.html

32 Los títulos de los cursos fueron: "Educación y formación en el contexto museístico. La utilización del Museo Pedagógico como recurso educativo" (2008); "Pedagogía museística: didáctica, virtualidad y difusión del patrimonio histórico-educativo" (2009); "Museos y educación: posibilidades didácticas para la difusión e interpretación del patrimonio cultural e históricoeducativo" (2010). Todos ellos, de 30 horas de duración, impartidos bajo el patrocinio del Vicerrectorado de Extensión Cultural y Relaciones Internacionales de la Universidad de Sevilla.
} 
Museos pedagógicos universitarios en ciudades educadoras del tiempo presente: divulgación del patrimonio histórico educativo

Pablo Álvarez Domínguez

Ciencia ${ }^{33}$ o diálogos científicos con la sociedad. Muy significativa ha sido al mismo tiempo la participación del museo en programas de radio ${ }^{34}$ nacionales e internacionales, y en encuentros intergeneracionales ${ }^{35}$ orales entre abuelos/asnietos/as, organizados en la misma sede del museo. Otra actividad destacable al respecto, se centra en la organización de actividades teatrales ligadas a recordar, por ejemplo, los juegos de la infancia a través de actuaciones de payasos flamencos ${ }^{36}$.

d) Imagen

En cuanto a este aspecto, resulta reseñable en primer lugar, la edición del documental "El Museo Pedagógico de la Facultad de Ciencias de la Educación de la Universidad de Sevilla: un espacio para compartir historias" (2014) ${ }^{37}$, un trabajo que refleja con detalle y a través de imágenes acompañadas de voz, la impronta del museo y el conjunto de acciones y actividades que se desarrollan desde el punto de vista divulgativo para llegar a la ciudadanía. Junto a ello, hay que mencionar la creación de un recurso DVD de Realidad Extendida "El Museo Pedagógico: un paseo por la Historia de la Educación” (2018) ${ }^{38}$, en aras de ofrecer a la sociedad una visita virtual a las instalaciones del Museo Pedagógico a través de Realidad Aumentada. En segundo lugar, hay que señalar el protagonismo que se le ha dado al cine histórico educativo en el museo, lo que se ha materializado a través de la organización de Cine Forum abiertos al público y en los que se han facilitado miradas e imágenes retrospectivas al pasado de la educación a través de la participación de ponentes especialistas en cine y educación. En tercer lugar,

\footnotetext{
${ }^{33}$ Cfr. https://cafeconciencia.fundaciondescubre.es/

34 Mencionemos como ejemplos los siguientes: a) Programa "En Primera Persona", de Radio Nacional de España, dirigido por Sandra Camps, donde se emitió el reportaje titulado: Museo Pedagógico. La escuela del pasado desde el presente" (2020). Cfr. https://www.rtve.es/alacarta/audios/en-primera-persona/primera-persona-museo-

pedagogico-escuela-del-pasado-desde-presente-07-05-20/5572016/; b) Programa en RadioTvUNIBA, Radio ufficialedelle'UniversitàdegliStudi di Bari Aldo Moro (Italia), con el tema: "Ripercussioneacademicasociale e culturale del Museo Pedagógico nell'attualità" (2019). Cfr: www.casauniba.net/le-interviste

${ }^{35}$ Cfr. http://revista.muesca.es/experiencias15/364-encuentro-intergeneracional

${ }^{36} \mathrm{Cfr}$. https://www.youtube.com/watch? v=NhJZONJ3VHM

${ }^{37}$ Documental editado por el Secretariado de Recursos Audiovisuales y Nuevas Tecnologías (SAV) de la Universidad de Sevilla. El resultado puede visualizarse en la red Youtube, y cuenta con más de 2200 visualizaciones: https://www.youtube.com/watch? $v=u l 7 g R n y L t p / \& t=749 s$

${ }^{38}$ Cfr. http://institucional.us.es/museopedagogia/839-2/
} 
hay que hacer notar la celebración de un concurso nacional de dibujo y pintura, que ha tenido dos ediciones; la primera, bajo el lema "Una mirada crítica al pasado de la escuela" (2016), y la segunda, dedicada a propiciar "Una mirada crítica y científica a la educación de las niñas" (2017) ${ }^{39}$. En cuarto lugar, se ha de destacar la participación del equipo del museo en diferentes programas de televisión a través de reportajes y entrevistas, en el diseño de videos didácticos, o en grabaciones de testimonios/entrevistas a educadores/as reconocidos/as o a personas mayores que acudieron a la escuela del ayer. En quinto y último lugar, señalaremos una actividad didáctica que viene realizándose en el marco del museo desde su fundación, y que consiste en la recreación en video desde el presente de fotografías escolares del ayer, con el fin de crear conciencia patrimonial educativa entre los estudiantes de Ciencias de la Educación y sus familiares y vecinos ${ }^{40}$.

\section{e) Otros}

Junto a todo el grupo de actividades presentadas con anterioridad, señalamos finalmente, algunas otras que se han realizado desde el museo, y que por su generalidad, no se han integrado en las categorías anteriormente definidas. Así, han de considerarse además actividades como las siguientes. En primer lugar, señalar la participación del museo con diferentes talleres, exposiciones y otras actividades en ferias científicas y festivales de divulgación científica, como por ejemplo, la Noche Europea de los Investigadores/as "Mujeres y hombres que hacen Ciencia para ti”"1, la Fiesta de la Historia ${ }^{42}$, la Noche de los Museos ${ }^{43}$, las Jornadas de Puertas Abiertas de la Facultad de Ciencias de la Educación, el Salón del Estudiante y Ferisport44, etc. En segundo lugar, mencionar la organización de

\footnotetext{
${ }^{39}$ Pueden consultarse las bases del concurso, a modo de ejemplo, en: http://canalciencia.us.es/iconcurso-nacional-de-dibujo-y-pintura-una-mirada-critica-al-pasado-de-la-escuela/ Y las resoluciones de las dos ediciones celebradas en: http://canalciencia.us.es/i-concurso-nacionalde-dibujo-y-pintura-una-mirada-critica-al-pasado-de-la-escuela/;

http://revista.muesca.es/noticias-antiguas/3-newsflash/408-2017-07-20-15-51-16

${ }^{40}$ El tipo de estampas histórico educativas pueden visualizarse en el siguiente canal Youtube de patrimonio educativo: https://www.youtube.com/user/patrimonioeducativo

${ }^{41} \mathrm{Cfr}$. https://lanochedelosinvestigadores.fundaciondescubre.es/portada/

${ }^{42}$ Cfr. https://fiestadelahistoria.wordpress.com/la-fiesta-de-la-historia/

${ }^{43}$ Cfr. https://onsevilla.com/dia-internacional-museos-2019-sevilla

${ }^{44}$ Cfr. https://www.sadus.us.es/index.php/eventos/salon-de-estudiantes-y-ferisport
} 
eventos conmemorativos por parte del museo, así como de talleres y actividades didácticas destinadas principalmente al alumnado de Educación Primaria, Secundaria y Formación Profesional (ÁLVAREZ, REBOLLO; NÚÑEZ, 2016). En tercer lugar, señalar también actividades como las siguientes: ScapeRooms y otras experiencias de gamificación; yincanas en la calle; así como espectáculos con títeres y marionetas.

\section{Consideraciones finales: a modo de conclusión}

Una ciudad educadora que mira el futuro, es una ciudad que encuentra motivos y los convierte en proyectos: transforma el pesimismo en posibilidad, el individualismo en colaboración y cooperativismo, los problemas en soluciones, las alternativas en cambios, las ausencias en evidencias, los silencios en voces, los deseos en sueños, y la cultura patrimonial y educativa en un derecho público de todas y para todos. Así, una ciudad que quiere educar para el futuro, es una ciudad que ha de trabajar por reconocer el valor de la historia y la memoria educativa para el desarrollo del presente. Al respecto, queda pendiente asumir algunos retos importantes, que tienen que ver con estimular a las ciudades para que contribuyan a: a) Localizar e inventariar el patrimonio histórico educativo que se encuentra arrinconado o infravalorado; b) Establecer planes y mecanismos para protegerlo; y c) Favorecer la visibilización, difusión y transferencia del patrimonio educativo a través de actividades culturales y de divulgación del conocimiento.

Acercar la disciplina histórico educativa a la sociedad es una responsabilidad que tienen que asumir todos/as los/as historiadores/as de la educación, profesores/as en universidades públicas y/o privadas, y sobre todo, los/as que reciben fondos públicos para el desarrollo de sus investigaciones. Desde la Historia de la Educación tenemos que seguir buscando razones para emprender proyectos de divulgación científica, oportunidades para llevarlos a término, y estrategias para ejecutarlos a través de prácticas pedagógicas, actividades y recursos. Y en este sentido, no cabe duda de que los/as historiadores/as de la educación encontramos en los museos pedagógicos integrados en las Universidades, potenciales recursos que nos permiten acercar 
La Historia de la Educación a la sociedad. Los/as historiadores/as de la educación tenemos que ayudar a los museos pedagógicos universitarios a interpretar su propia singularidad y a poner en valor su idiosincrasia. Y en este contexto, los museos tendrán que reinventarse si quieren legitimarse en un modelo de sociedad en el que el acceso a la cultura y su disfrute no se encuentran entre las prioridades de la ciudadanía. Por ello, plantear propuestas participativas que permitan la divulgación, el contacto y la interacción con quienes nos conocen y visitan, sigue resultando fundamental, pero además, queda mucho por hacer en relación con quienes ni siquiera conocen la existencia de estos museos.

La mayoría de los museos pedagógicos existen gracias al esfuerzo desinteresado de profesores universitarios, sobre todo, que dedica parte de su tiempo docente, investigador y de ocio a rescatar objetos olvidados, inventariarlos, catalogarlos y presentarlos al público de la mejor manera, a pesar de los escasos recursos con lo que normalmente y en estos casos se cuenta. Sin embargo, los museos pedagógicos universitarios merecen aún mayor atención por parte de las universidades. Lo demandamos los/as historiadores/as de la educación, y han de demandarlo las futuras generaciones, que tendrán en la cultura y el conocimiento sus bienes más preciados.

La falta de repercusión de los resultados de los proyectos museístico pedagógicos de la comunidad de historiadores/as de la educación española, conlleva entre otras cosas, que en Europa no le estemos sacando el máximo partido a nuestros trabajos y esfuerzos. No obstante, en casi una década de existencia, el Museo Pedagógico de la Facultad de Ciencias de la Educación de la Universidad de Sevilla ejemplifica claramente el desarrollo de un amplio conjunto de acciones y procesos ligados a la divulgación científica en el ámbito de la Historia de la Educación como área de conocimiento integrada en las Ciencias Sociales; lo que nos lleva a considerarlo, a pesar de sus escasos recursos económicos, como un modesto ejemplo de éxito en lo que se refiere a la tarea de transferir y trasladar lo académico a lo divulgativo ${ }^{45}$.

\footnotetext{
${ }^{45}$ El hecho de centrarnos en este estudio en el caso del Museo Pedagógico de la Facultad de Ciencias de la Educación de la Universidad de Sevilla, no significa que el resto de museos pedagógico universitarios españoles no desarrollen una importante función de divulgación del patrimonio histórico educativo. Todo lo contrario, pues la mayor parte de ellos desarrollan una labor encomiable en este sentido.
} 
El conocimiento de la Historia de la Educación y la recuperación del patrimonio educativo no puede ser un acto finalista en sí mismo. Por el contrario,

debe convertirse en la pieza clave para la construcción de un futuro educativo en el que los museos pedagógicos universitarios lleguen a convertirse -en el marco de una ciudad educadora-, en agentes de dinamización social y divulgación cultural e histórico educativa. Y para ello, hay que trabajar diseñando y desarrollando un amplio repertorio de actividades de divulgación, lo suficientemente atrayentes y adaptadas a diferentes tipos de públicos, como para dinamizarlos aún más, enriqueciéndolos con la visión y aportaciones de teorías educativas, paradigmas didácticos y acciones de divulgación cultural.

\section{Referências}

ALCÍBAR, Miguel. Comunicación pública de la ciencia y la tecnología: una aproximación crítica a su historia conceptual. Arbor: ciencia pensamiento y cultura, Madrid, v. 191, n. 773, p. 1-13, 2015.

ALARCÓN, Eva. La divulgación científica en Europa. Uciencia: revista de divulgación científica de la Universidad de Málaga, n. 11, p. 48-49, jun. 2013.

ALFIERI, Fiorenzo. Los recursos educativos de la ciudad. In: CONGRESO INTERNACIONAL DE CIUDADES EDUCADORAS, 1., 1991, Barcelona. Documentos finales [...]. Barcelona: Ayuntamiento de Barcelona, 1991.

ALONSO, Luis; GARCÍA, Isabel. Diseño de exposiciones: concepto, instalación y montaje. Madrid: Alianza Editorial, 2010.

ÁLVAREZ, Pablo. Los museos pedagógicos en España: entre la memoria y la creatividad. Gijón: Trea y EUS, 2016.

ÁlVAREZ, Pablo; NúÑEZ, Marina; REBOLLO, Maria José. El museo pedagógico de la facultad de ciencias de la educación de la universidad de Sevilla: una obra en tres actos. In: ÁLVAREZ, Pablo (ed.). Los museos pedagógicos en España: entre la memoria y la creatividad. Gijón: Trea y EUS, 2016. p. 33-46.

ÁLVAREZ, Pablo; PAYÀ, Andrés. Los museos pedagógicos universitarios en España: tradición y futuro ante la difusión del patrimonio histórico educativo. In: RIVERA, R. Daniel; GARCÍA, Isabel (coords.). In: CONGRESO INTERNACIONAL 
MUSEOS UNIVERSITARIOS, 1., 2015, Madrid. Actas [...]. Madrid: CIMU, 2015. p. 237242. Tema: Tradición y futuro.

ANDER-EGG, Ezequiel. La ciudad educadora como forma de fortalecimiento de la democracia y de una ciudadanía activa y convivencial. Córdoba (Argentina): Editorial Brujas, 2008.

ANDRADE, Liliana. A cidade enquanto ferramenta didática ao serviço do ensino da história. In: GUZMÁN, María (coord.). Patrimonio y educación una propuesta integradora. Granada, Junta de Andalucía: Universidad de Granada y Grupo de Investigación Patrimonio y Educación (HUM-221), 2016. p. 245-247.

ARIÑO, Antonio. The cultural mission of universities. Debats, Valencia, v. 131, n. 2, p. 81-102, 2017.

ARIÑO, Antonio. Entre la candidesa i el cinisme: comunicar la ciència en el segle XXI. Mètode: Revista de difusió de la investigació, Valencia, v. 1, n. 100, p. 38-45, 2019.

ASCENZI, Anna; BRUNELLI, Marta; MEDA, Juri. School museums as dynamic áreas for widening the heuristic potential and the socio-cultural impact of the history of education. a case study from Italy. Paedagogica Historica:

International Journal of the History of Education, 10 dec. 2019. Disponible en: https://doi.org/10.1080/00309230.2019.1660387. Acceso en: 1 abr. 2020.

BELENGUER, Mariano. Información y divulgación científica: dos conceptos paralelos y complementarios en el periodismo científico. Estudios sobre el Mensaje Periodístico, Madrid, n. 9, p. 43-53, 2003.

BORDIGNON, Fernando Raúl. Laboratorios de innovación ciudadana, espacios para el hacer digital crítico: virtualidad, educación y ciencia. In: GUZMÁN, María (coord.). Patrimonio y educación una propuesta integradora. Granada, Junta de Andalucía: Universidad de Granada y Grupo de Investigación Patrimonio y Educación (HUM-221), 2016. p. 293-300.

BOSCH, Eulàlia (ed.). Educación y vida urbana: 20 años de ciudades educadoras. Madrid: Santillana, 2008.

BOYER, Myriam. Les musées de l'école et de l'éducation: un champ muséal quantitativement significatif mais difficile à cerner. Muséologies, Montréal (Québec), n. 52, p. 104-129, 2011.

CALVO, Manuel. Objetivos y funciones de la divulgación científica. Acta. Manual formativo, Madrid, n. 40, p. 99-106, 2006. 
CAMPS, Victoria. La fragilidad de una ética liberal. Barcelona: Ediciones UAB, 2018.

COMA, Laia; SANTACONA, Joan. Ciudad educadora y patrimonio: cookbook of heritage. Gijón: Trea, 2010.

DAMIANO, Elio. Didatticaed epistemología. Pedagogia e vita, Roma, n. 4, p. 75106, Luglio/ag. 2004.

DÁVILA, Paulí; NAYA, Luís M. El museo de la educación de la universidad del País Vasco. Historia de la Educación: Revista Interuniversitaria, Salamanca, n. 36, p. 482-485, 2017.

DEL POZO, Juan Manuel. El concepto de ciudad educadora, hoy. In: BOSCH, Eulàlia (ed.). Educación y vida urbana: 20 años de ciudades educadoras. Madrid: Santillana, 2008. p. 25-31.

DÍEZ, Enrique Javier; RODRÍGUEZ, Juan Ramón. La “polis” secuestrada: propuestas para una ciudad educadora. Gijón: Trea, 2018.

ESCOBAR-ORTÍZ, Jorge M. La apropiación social de la ciencia y la tecnología como eslogan: un análisis del caso colombiano. Revista Iberoamericana de Ciencia, Tecnología y Sociedad, Buenos Aires, n. 13, v. 38, p. 29-57, 2018. Disponible en: http://ojs.revistacts.net/index.php/CTS/article/view/65. Acceso en: 1 abr. 2020.

ESCOBAR-ORTíZ, Jorge M.; RINCÓN-ÁLVAREZ, Andrés. La divulgación científica y sus modelos comunicativos: algunas reflexiones teóricas para la enseñanza de las ciencias. Revista Colombiana de Ciencias Sociales, Medellín, n. 10, v. 1, p. 135154, 2019.

ESCOLANO, Agustín. Sherlock Holmes goes to school. Etnohistory of school and educationalheritage. History of Education \& Children's Literature, Macerata, v. 2, p. 17-32, 2010.

FERNÁNDEZ, Magda. Los museos, espacios de cultura, espacios de aprendizaje. IBER. Didáctica de las Ciencias Sociales, Geografía e Historia, Barcelona, n. 36, p. 55-61, abr./jun. 2003.

FREITAS, Normanda. Uma reflexao sobre patrimonio. Revista do Professor: Museu da República, Rio de Janeiro, n. 1, p. 4-7, 2009.

GARCÍA, Sol. Los retos de los museos en el siglo XXI, según sus responsables. ARS Magazine: Revista de Arte y Coleccionismo, Madrid, n. 47, p. 1-2, 2020. Disponible en: https://arsmagazine.com/los-retos-de-los-museos-en-el-sigloxxi-segun-sus-directores/. Acceso en: 20 abr. 2020. 
GÓMEZ, María Nieves. Acerca del concepto de museo pedagógico: algunos interrogantes. In: JIMÉNEZ, Alfredo et al. (coord.): Etnohistoria de la escuela: XII Coloquio Nacional de Historia de la Educación. Burgos: Universidad de Burgos, Sociedad Española de Historia de la Educación, 2003. p. 817-828.

GONZÁLEZ, Teresa. Los Museos Pedagógicos. Museos vivos de la Educación. El día digital, Castilla La Mancha, p. 12, 31 agosto, 2000. Disponible en: https://eldiadigital.es/. Acceso en: 20 abr. 2020.

GUZMÁN, María (coord.). Patrimonio y educación: una propuesta integradora. Granada, Junta de Andalucía: Universidad de Granada y Grupo de Investigación Patrimonio y Educación (HUM-221), 2016.

HAMEL, Jacques; DUFOUR, Stephane; FORTIN, Dominic. Case studymethods. California: Sage Publications, 1993.

HARRIS, Marvin. Teorías sobre la cultura en la era posmoderna. Barcelona: Crítica, 2007.

JUAN, Víctor. Museos Pedagógicos: la memoria recuperada. Huesca: Museo Pedagógico de Aragón, 2008.

LASCURAIN, María Luisa; SANZ, Elías. La divulgación científica en el entorno universitario. In: MANUEL, María; SANZ, Elías (coords.). ENCONTRO IBÉRICO EDIBCIC, 4., 2009, Coimbra. Actas [...]. Coimbra: Universidade de Coimbra, 2009. v. 1, p. 507-515. Tema: A ciência da informação criadora de conhecimento.

LÓPEZ, Ramón. Historia de la escuela y cultura escolar: dos décadas de fructíferas relaciones. La emergente importancia del estudio sobre el patrimonio escolar. Cuestiones Pedagógicas, Sevilla, n. 22, p. 17-42, 2013.

MARTíN, Bienvenido; RAMOS, Isabel. La vida y el pensamiento del docente: testimonio de la memoria, patrimonio educativo: Museo pedagógico de la universidad de Salamanca. In: JUAN, Víctor. Museos Pedagógicos. La memoria recuperada. Huesca: Museo Pedagógico de Aragón, 2008. p. 69-80.

MAYORDOMO, Alejandro. El legado de las voces y los escritos: su valor como testimonio de la cultura escolar. Ridphe-R: Revista Iberoamericana de Patrimonio Educativo, Campinas, v. 6, p. 1-31, 2020. Disponible en: https://econtents.bc.unicamp.br/inpec/index.php/ridphe/article/view/13504/884 ‥ Acceso en: 10 abr. 2020.

MEDA, Juri. Musei della scuola e dell'educazione: ipotesi progettuale per una sistematizzazione delle iniziative di raccolta, conservazione e valorizzazione dei beni culturali delle scuole. History of Education \& Children's Literature, Macerata, v. 5, n. 2, p. 489-501, 2010. 
MEDINA, Miguel Ángel. La divulgación también es ciencia, la divulgación también es educación. Encuentros en la Biología, Málaga, v. 5, n. 138-139, p. 17-18, 2012.

MENDIZÁBAL, Gabriela. Divulgación de las Ciencias Sociales. Inventio, Morelos, n. 26, p. 1-2, 2016.

MENEZES, Maria Cristina (org.). Desafios Iberoamericanos: o patrimônio histórico-educativo em rede. Campinas: CIVILIS/UNICAMP-RIDPHE-CME/USP, 2016.

MARTÍNEZ, Silvia et al. Didáctica patrimonial y difusión de la cultura. In: GUZMÁN, María (coord.). Patrimonio y educación una propuesta integradora. Granada, Junta de Andalucía: Universidad de Granada y Grupo de Investigación Patrimonio y Educación (HUM-221), 2016. p. 329-335.

MOGARRO, Maria Joao. Educaçao e patrimonio cultural: escolas, objetos e practicas. Lisboa: Ediçoes Colibri; Instituto de Educação, 2015.

MORENO, Pedro Luis. La historiografía del patrimonio educativo en España: un balance crítico. Educar em Revista, Curitiba, n. 58, p. 87-102, 2015.

PAREJO, Macarena; MARTÍN, Daniel; VIVAS, Agustín. La divulgación científica: estructuras y prácticas en las universidades. Barcelona: Gedisa, 2017.

PÉREZ, Patricia. ¿La ciudad puede llegar a ser educadora? Iconos. Revista de Ciencias Sociales, Quito, n. 23, p. 127-142, sept. 2005.

PERRAULT, Sarah. Communicating popular science: from deficit to democracy. New York: palgrave macmillan, 2013.

POSSAMAI, Zita Rosane. Patrimônio e história da educação: aproximações e possibilidades de pesquisa. História da Educação, Pelotas: UFPel, v. 16, p. 127139, 2012.

POSSAMAI, Zita Rosane. O lugar do patrimônio na operação historiográfica e o lugar da história no campo do patrimonio. Anos 90, Rio Grande do Sul, v. 25, n. 48, p. 23-49, 2018.

PUEBLA, Florencia. Los estudios de público como herramientas para analizar la relación entre sociedad y patrimonio. Intervención, Ciudad de México, n. 8, p. 1325, jul/dic. 2013.

QUIÑÓNEZ, Herly A. Divulgación científica y tecnología: teoría y práctica periodística para la producción del documental”. Razón y Palabra, Monterrey, n. 77, agosto/oct. 2011. Disponible en: 
http://www.razonypalabra.org.mx/varia/77\%20

5a\%20parte/70_Quinonez_V77.pdf. Acceso en: 22 abr. 2020.

RABAZAS, Teresa; RAMOS, Sara. El laboratorio/museo de historia de la educación "M.B. Cossío" de la facultad de educación de la UCM. Estado de las colecciones y líneas de actuación. In: MENEZES, Maria Cristina (org.). Desafios Iberoamericanos: o patrimônio histórico-educativo em rede. Campinas: CIVILIS/UNICAMP-RIDPHE-CME/USP, 2016. p. 229-256.

RABAZAS, Teresa; RAMOS, Sara. Los museos pedagógicos universitarios como espacios de memoria y educación. História da Educação, Rio Grande do Sul, n. 53, v. 21, p. 100-119, 2017.

RAICHVARG, Daniel; JACQUES, Jean. Savants et ignorants: une histoire de la vulgarisation des sciences. Francia: Seuil, 1992.

RUíZ, Julio. Historia y museología de laeEducación: despegue y reconversión de los museos pedagógicos. Historia de la educación: Revista interuniversitaria, Salamanca, n. 25, p. 271-290, 2006.

RUíz, Julio. El patrimonio histórico-educativo: su conservación y estudio. Madrid: Biblioteca Nueva, 2010.

SANTACANA, Joan; HERNÁNDEZ, Francisco J. Museología crítica. Gijón, TREA Ediciones, 2006.

SCE: SEVILLA, CIUDAD EDUCADORA. Actuación educativa. Sevilla: Delegación de Educación y Gobierno Interior, Ayuntamiento de Sevilla, 2006.

SILVA, Alexandra L. da; ORLANDO, Evelyn de A. Memória e patrimônio na história da educação: possibilidades e desafíos. Cadernos de História da Educaçao, Ubèrlandia, v. 18, n. 2, p. 425-444, 2019.

SOLANAS, Isabel, MARTORELL, Cristina; SERRA, Carolina. La divulgación científica en ciencias sociales a través de las exposiciones: un estudio de caso. Historia y Comunicación Social, Madrid, v. 18, p. 815-826, nov. 2013. Número especial.

TRILLA, Jaume. Ciudades educadoras: bases conceptuales. In: SABBAG, Maria Amelia (org.). Cidades Educadoras. Curitiba: UFPR, 1997.

TONUCCI, Francesco. La ciudad de los niños: un modo nuevo de pensar la ciudad. Barcelona: Graó, 2015. 
TRENCHER, Gregory et al. Beyond the third mission: Exploring the emerging university function of co-creation for sustainability. Science and Public Policy, Londres, n. 2, v. 41, p. 151-79, 2014.

VIVAS, Agustín; PAREJO, Macarena; MARTÍN, Daniel. Divulgación científica y función social en las universidades. Madrid: Pirámide, 2018.

YACUZZI, Enrique. El estudio de caso como metodología de investigación: teoría, mecanismos causales, validación. Inomics, Berlín, n. 1, p. 296-306, 2005. 